Article

\title{
A Real-World, Observational, Prospective Study to Assess the Molecular Epidemiology of Epidermal Growth Factor Receptor (EGFR) Mutations upon Progression on or after First-Line Therapy with a First- or Second-Generation EGFR Tyrosine Kinase Inhibitor in EGFR Mutation-Positive Locally Advanced or Metastatic Non-Small Cell Lung Cancer: The 'LUNGFUL' Study
}

Giannis Mountzios 1,*(-), Anna Koumarianou ${ }^{2}\left(\mathbb{D}\right.$, Alexandros Bokas ${ }^{3}$, Dimitrios Mavroudis ${ }^{4}$, Epaminondas Samantas ${ }^{5}$, Evangelos Georgios Fergadis ${ }^{6}$, Helena Linardou ${ }^{7}$, Panagiotis Katsaounis ${ }^{8}$, Elias Athanasiadis ${ }^{9}$, Michalis V. Karamouzis ${ }^{10}$, George Pentheroudakis ${ }^{11}$, Sofia Lampaki ${ }^{12}$, Marios E. Froudarakis ${ }^{13}$ (i), Eleni-Isidora A. Perdikouri ${ }^{14}$, Alvertos Somarakis ${ }^{15}$, Foteini Papageorgiou ${ }^{16}$, Zoe Paparepa ${ }^{17}$, Aristeidis Nikolaou ${ }^{15}$ and Konstantinos N. Syrigos ${ }^{18}$

\section{check for}

updates

Citation: Mountzios, G.;

Koumarianou, A.; Bokas, A.;

Mavroudis, D.; Samantas, E.;

Fergadis, E.G.; Linardou, H.;

Katsaounis, P.; Athanasiadis, E.;

Karamouzis, M.V.; et al. A Real-

World, Observational, Prospective

Study to Assess the Molecular

Epidemiology of Epidermal Growth

Factor Receptor (EGFR) Mutations

upon Progression on or after

First-Line Therapy with a First- or Second-Generation EGFR Tyrosine Kinase Inhibitor in EGFR MutationPositive Locally Advanced or

Metastatic Non-Small Cell Lung

Cancer: The 'LUNGFUL' Study.

Cancers 2021, 13, 3172. https://

doi.org/10.3390/cancers13133172

Academic Editor: Roberta Alfieri

Received: 25 April 2021

Accepted: 21 June 2021

Published: 25 June 2021

Publisher's Note: MDPI stays neutral with regard to jurisdictional claims in published maps and institutional affiliations.

Copyright: (c) 2021 by the authors. Licensee MDPI, Basel, Switzerland.
1 Fourth Oncology Department and Clinical Trials Unit, Henry Dunant Hospital Center, 11526 Athens, Greece

2 Hematology-Oncology Unit, Fourth Department of Internal Medicine, Attikon University Hospital, National and Kapodistrian University of Athens, 12462 Athens, Greece; akoumari@yahoo.com

3 First Department of Clinical Oncology, Theagenio Cancer Hospital, 54007 Thessaloniki, Greece; a.pathologiki@theagenio.gov.gr

4 Department of Medical Oncology, University Hospital of Heraklion, 71110 Crete, Greece; mavrudis@med.uoc.gr

5 2nd Oncology Department, Metropolitan Hospital, 18547 Athens, Greece; epsam@otenet.gr

6 Medical Oncology Department, Metaxa Cancer Hospital, 18537 Piraeus, Greece; e.fergadis@windowslive.com

7 4th Oncology Department \& Comprehensive Clinical Trials Center, Metropolitan Hospital, 18547 Athens, Greece; elinardou@metropolitan-hospital.gr

8 Oncology Department, Metropolitan Hospital, 15562 Athens, Greece; pvkatsaounis@gmail.com

9 Department of Medical Oncology, Mitera Hospital, 15123 Athens, Greece; iathanasiadis@hygeia.gr

10 Molecular Oncology Unit, Department of Biological Chemistry Medical School, 11525 Athens, Greece; m.karamouzis@imibe.org

11 Department of Medical Oncology, Medical School University of Ioannina, 45500 Ioannina, Greece; gpenther@otenet.gr

12 Pulmonary Department, General Hospital 'G. Papanikolaou', Aristotle University of Thessaloniki, 57010 Thessaloniki, Greece; pneumon-kliniki@auth.gr

13 Department of Respiratory Medicine, Medical School of Alexandroupolis Democritus University of Thrace, 68100 Alexandroupolis, Greece; mfroud@med.duth.gr

14 Oncology Department, General Hospital 'Papageorgiou', Aristotle University of Thessaloniki, 56429 Thessaloniki, Greece; cpapandreou@auth.gr

15 Medical Affairs Department, AstraZeneca, 15123 Athens, Greece; alvertos.somarakis@astrazeneca.com (A.S.) aristeidis.nikolaou@astrazeneca.com (A.N.)

16 Diagnostics Function Oncology, AstraZeneca, 15123 Athens, Greece; Fotini.Papageorgiou@astrazeneca.com

17 Clinical Operations, AstraZeneca, 15123 Athens, Greece; Zoi.Paparepa@astrazeneca.com

18 Third Department of Medicine, National and Kapodistrian University of Athens, School of Medicine, Sotiria Hospital, 11527 Athens, Greece; ksyrigos@med.uoa.gr

* Correspondence: ioamoun@dunant.gr; Tel.: +30-6983519989; Fax: +30-2106972274

Simple Summary: Non-small cell lung cancer (NSCLC) accounts for approximately $85 \%$ of lung cancer cases, with few patients carrying driver mutations in the gene encoding for epidermal growth factor receptor (EGFR). Advances in translational research have established EGFR tyrosine kinase inhibitors (TKIs) as the standard first-line therapy for NSCLC patients with activating EGFR mutations. The aim of our observational study was to assess the frequency of T790M acquired resistance and predictors of its presence, in patients with EGFR-mutated locally advanced or metastatic NSCLC who have progressed in the first-line EGFR-TKI treatment setting with first- or second-generation TKIs and have undergone molecular testing in tissue and/or plasma biopsy. The study highlights the challenges of performing tissue re-biopsy in routine care settings, which can lead to patients 
This article is an open access article distributed under the terms and conditions of the Creative Commons Attribution (CC BY) license (https:// creativecommons.org/licenses/by/ $4.0 /)$. considered non-eligible for certain therapies from which they can benefit, and merits further actions from the healthcare community, in order to establish re-biopsy as a standard procedure.

Abstract: Background: Real-world data on the molecular epidemiology of EGFR resistance mutations at or after progression with first- or second-generation EGFR-TKIs in patients with advanced NSCLC are lacking. Methods: This ongoing observational study was carried out by 23 hospital-based physicians in Greece. The decision to perform cobas ${ }^{\circledR}$ EGFR Mutation Test v2 in tissue and/or plasma at disease progression was made before enrollment. For patients with negative/inconclusive T790M plasma-based results, tissue re-biopsy could be performed. Results: Ninety-six (96) eligible patients were consecutively enrolled (median age: 67.8 years) between July-2017 and September-2019. Of the patients, $98 \%$ were tested upon progression using plasma and $2 \%$ using tissue/cytology biopsy. The T790M mutation was detected in $16.0 \%$ of liquid biopsies. Tissue re-biopsy was performed in $22.8 \%$ of patients with a T790M-negative plasma result. In total, the T790M positivity rate was $21.9 \%$, not differing between patients on first- or second-generation EGFR-TKI. Higher $(\geq 2)$ ECOG performance status and longer ( $\geq 10$ months) time to disease progression following EGFR-TKI treatment initiation were associated with T790M positivity. Conclusions: Results from plasma/tissue-cytology samples in a real-world setting, yielded a T790M positivity rate lower than previous reports. Fewer than one in four patients with negative plasma-based testing underwent tissue re-biopsy, indicating the challenges in routine care settings.

Keywords: biopsy; carcinoma; non-small-cell lung cancer; EGFR-tyrosine kinase inhibitor; epidermal growth factor receptor; T790M mutation

\section{Introduction}

In 2018, tracheal, bronchus and lung cancer ranked as the leading cause of cancerrelated deaths worldwide and in Greece, a country which ranked fourth among 185 countries in terms of age-standardized incidence rate of lung cancer $(40.5$ per 100,000$)[1,2]$. Non-small cell lung cancer (NSCLC) accounts for approximately $85 \%$ of lung cancer cases, with few patients carrying driver mutations in the gene encoding for epidermal growth factor receptor (EGFR) [3]. Advances in translational research have established EGFR tyrosine kinase inhibitors (TKIs) as the standard first-line therapy for NSCLC patients with sensitizing EGFR mutations [3]. Administration of EGFR-TKI therapy has been associated with improved outcomes and quality of life compared with doublet chemotherapy in EGFR-mutant NSCLC [4-8].

We have to take into consideration that currently, after FLAURA's study data release, the study that compared osimertinib vs erlotinib or gefitinib in 1st line treatment, osimertinib is recommended by European Society of Medical Oncology (ESMO) guidelines, as 1st line treatment in patients expressing sensitizing mutation of EGFR and patient expressing T790M as de novo mutation (I, A; MBCS score v1.1 score: 4) [3,9]. During the recruitment period of this study, as osimertinib was not available as 1st line treatment, except for patients harboring the de novo T790M point mutation, there was no general consensus for a preference of any of the available first- and second-generation EGFR-TKIs in the first-line setting [3]. In fact, in the randomized phase IIB LUX-Lung 7 trial, similar overall survival (OS) but significantly better objective response rates (ORR)and progression-free survival (PFS) were reported for the second-generation EGFR-TKI afatinib versus the first-generation gefitinib [10,11]. Similarly, in the randomized phase III ARCHER 1050 trial, the second-generation TKI dacomitinib (not available in Greece) was shown to significantly improve PFS over the first-generation EGFR-TKI, gefitinib [12,13].

Importantly, approximately 20 to $40 \%$ of EGFR-mutated NSCLC patients experience primary resistance to first- or second- generation EGFR-TKIs, commonly attributed to genetic alterations, such as exon 20 insertions and the de novo T790M point mutation [14-17]. In addition, even among patients with an initial response, the majority progress after 9 
to 14 months of treatment with a first- or second-generation EGFR-TKI [10-13]. Several mechanisms have been implicated in the development of acquired resistance to EGFR-TKIs, with acquisition of the T790M mutation considered the most prominent [18-20], detected in up to $50 \%$ of patients treated with first- or second-generation EGFR-TKIs [20-24]. For patients with systemic progression and a confirmed T790M mutation either with tissue biopsy or circulating-tumor DNA (ctDNA) plasma testing (and tissue re-biopsy if plasma test is negative), administration of the third generation EGFR-TKI, osimertinib, is the treatment of choice, while for patients who cannot undergo tissue biopsy or for whom a T790M mutation is not detected, the contemporary ESMO guidelines recommend switching to platinum-based chemotherapy $[3,25,26]$.

As a result, tailoring of subsequent therapy among patients with acquired resistance to first-line EGFR-TKI requires knowledge of the T790M mutation status. Mutational analysis of EGFR can be performed both in tissue and liquid biopsy, with the clinical utility of the latter recognized in several clinical trials [27]. In addition to being minimally invasive and easily repeatable, the assessment of ctDNA addresses the bias stemming from the molecular heterogeneity of tumor samples and overcomes the difficulties of performing tissue re-biopsy, including, but not limited to, patient refusal, absence of a lesion amenable to re-biopsy, and safety concerns due to the patients' declining performance status/old age $[3,28,29]$. While EGFR testing in tissue is widely available in Greece, either as a single testing or as part of a broader molecular profiling, plasma testing for detection of EGFR mutations in ctDNA is not yet reimbursed, resulting in access difficulties.

In light of the above, the 'LUNGFUL' observational study was designed to assess the frequency of T790M acquired resistance and predictors of its presence, in patients with EGFR-mutated locally advanced or metastatic NSCLC who have progressed in the first-line EGFR-TKI treatment setting with first- or second-generation TKIs and have undergone molecular testing using the FDA-approved cobas ${ }^{\circledR}$ EGFR Mutation Test v2 in tissue and/or plasma biopsy. These objectives were analyzed during the study's interim analysis in the total study sample size, the results of which are presented herein.

\section{Patients and Methods}

\subsection{Study Design and Setting}

This is an ongoing non-interventional, single-country, multicenter, prospective cohort study, based on primary data collection, of patients with locally advanced or metastatic EGFR mutation-positive NSCLC who had been treated with a first- or second-generation EGFR-TKI in the first-line setting and for whom the physicians had decided, prior to enrollment, to perform tissue and/or plasma-based liquid biopsy, using the cobas ${ }^{\circledR} E G F R$ Mutation Test v2, at the time of disease progression in the first-line setting.

The study is carried out by hospital-based physicians under real-world conditions of daily clinical practice. In addition, in order to represent variations in current real-world patterns of care, research sites were recruited from various geographic regions in Greece, also taking into consideration the regional setting and type of healthcare site/institution (publicly/privately owned, specialized oncology/pulmonology clinic, university clinic). The overall study duration period is approximately 36 months, including a 24-month recruitment period. The study design is presented in Figure 1. 

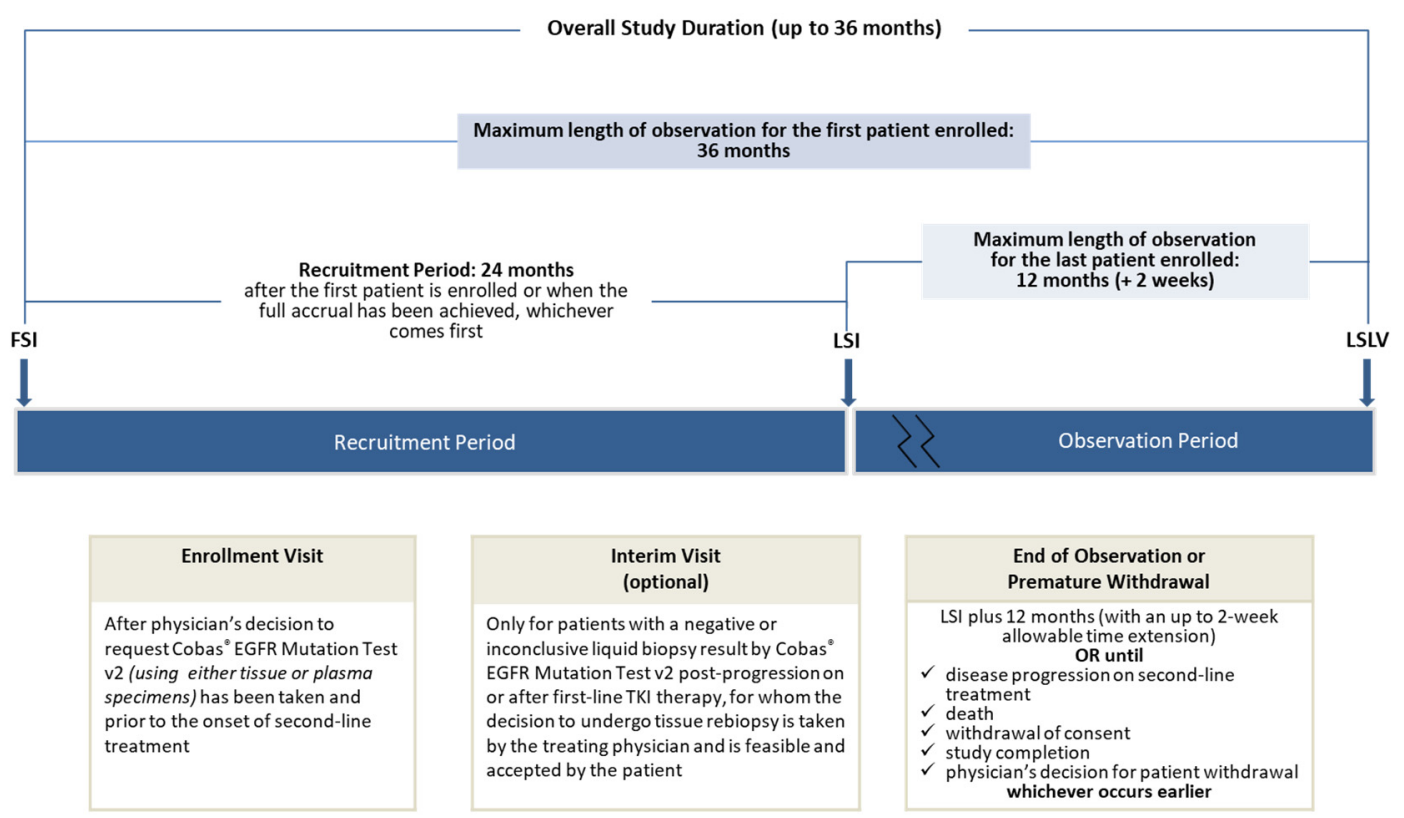

Figure 1. Overview of the study design. FSI: First Subject In; LSI: Last Subject In; LSLV: Last Subject Last Visit.

\subsection{EGFR Mutation Testing}

All molecular pathology laboratories carrying out EGFR mutation testing applied cobas $^{\circledR}$ EGFR Mutation Test v2. For blood collection, cell-free DNA blood collection tubes (cfDNA BCTs; Streck, Nembraska, NE, USA) were used according to the manufacturer's instructions, in order to ship $10 \mathrm{~mL}$ of whole blood at ambient temperatures $\left(15-25^{\circ} \mathrm{C}\right)$. cfDNA BCTs were previously shown to retain the integrity of the cfDNA and stability of blood cells preventing dilution of circulating tumor DNA (ctDNA) with wild-type genomic DNA [30]. The isolation of circulating free DNA was carried out with cobas ${ }^{\circledR}$ cfDNA sample preparation kit (Roche Diagnostics, Pleasanton, CA, USA). The detection of EGFR mutations was performed with cobas $^{\circledR}$ EGFR Mutation Test v2 as per manufacturer's instructions (Roche Diagnostics). Briefly, $2 \mathrm{~mL}$ of plasma was used to extract cfDNA using cobas ${ }^{\circledR}$ cfDNA Sample Preparation Kit. The target DNA was then amplified and detected on the cobas z 480 analyser (Roche Diagnostics) using the amplification and detection reagents provided in the cobas ${ }^{\circledR}$ EGFR Mutation Test v2 kit (Roche Diagnostics). Data analysis was automatically performed by EGFR Plasma Analysis Package Software version 1.0 (Roche Diagnostics) [31]. As per the analytical/non clinical evaluation of this test, a limit of detection of 100 copies/mL for T790M in plasma spiked with sheared cell line DNAs was reported [31].

Both kits are FDA approved as companion diagnostics (CoDx) in order to identify EGFR mutations (incl. T790M) in the plasma of patients with NSCLC in order to identify eligible patients for treatment with the TKI inhibitors erlotinib and osimertinib, [32,33]. As per its clinical evaluation, the cobas ${ }^{\circledR}$ EGFR Mutation Test v2 for plasma, was used in the majority of clinical trials supporting osimertinib's use in resistance T790M setting, namely AURA extension and AURA2 phase II and AURA III phase 3 trial. With cobas tissue test results as a reference, the plasma T790M positive percent agreement (PPA) was $61 \%$ and $51 \%$ by cobas plasma, in AURA II and AURA III respectively [34,35].

Disease progression could have occurred during or after discontinuation of the EGFRTKI regimen received in the first-line setting.

The results of the interim analysis are presented in this work, which includes analysis of data collected during the enrollment visit and the optional interim visit in the full study sample.

The study mainly involves collection of primary data, obtained prospectively during the study visits as performed per standard clinical practice or through patient self-report. 
Data regarding the patient's medical and lung cancer-related history are abstracted from patient medical charts/records. Data are recorded on a web-based data capture system specifically designed for the needs of the study, which adheres to all applicable data protection regulations and requirements with regard to electronic records and database validation.

The study was designed and is being conducted in compliance with all applicable local laws and regulations, the Good Pharmacoepidemiology Practices of the International Society for Pharmacoepidemiology and the ethical principles laid down in the Declaration of Helsinki. The study was approved by the Institutional Review Boards of the participating hospital sites. All patients provided written informed consent.

\subsection{Study Population}

The study population includes outpatients, aged at least 18 years at the time of informed consent, with histologically- or cytologically-documented EGFR mutation-positive locally advanced or metastatic (IIIB-C/IV) NSCLC (according to the staging criteria used by the physicians in their routine practice) of any histological type who had progressed (per Investigator's assessment) on or after first-line treatment with a first- or second- generation EGFR-TKI approved in Greece (namely erlotinib, gefitinib and afatinib), and for whom the decision to undergo tissue or plasma-based liquid biopsy, using the cobas EGFR Mutation Test v2, after confirmation of disease progression had been taken prior to their enrollment in the study and was separated from the physician's decision to include the patient in this study. Prior adjuvant and neo-adjuvant chemotherapy or radiotherapy, as well as prior platinum-based chemotherapy in the context of first-line treatment for advanced/metastatic disease was allowed, provided that EGFR-TKI was administered as maintenance therapy following disease control achievement. Patients who at the time of tissue biopsy or plasma-based liquid biopsy had initiated second-line treatment were excluded from study participation. For the purposes of the study, second-line treatment was defined as switch to or addition of another agent, regardless of the drug class, including EGFR-TKI re-challenge with intervening chemotherapy. Continuation of the same EGFRTKI, local therapy (surgery, radiotherapy) and best supportive care were not considered second-line treatment.

\subsection{Study Objectives}

The primary objective of the study was to assess the frequency of the T790M mutation, using the cobas EGFR Mutation Test v2 at the time of progression on or after first-line first- or second-generation EGFR-TKI therapy. Secondary objectives, applicable to the present analysis, were to determine the frequency of EGFR T790M-mediated primary and acquired (secondary) resistance to first-line EGFR-TKI therapy; to depict the patients' EGFR molecular profile; to evaluate molecular testing patterns, in terms of biopsy type (tissue re-biopsy or plasma-based liquid biopsy), biopsy timing, and collection site; and to identify potential patient and clinicopathological predictive factors for T790M mutation status at the time of disease progression in the first-line setting.

\subsection{Relevant Definitions}

Index diagnosis with advanced (IIIB-IV) NSCLC was defined as the diagnosis of the disease stage present at the time of EGFR-TKI initiation in the first-line treatment setting. In case a patient had transitioned to a higher advanced disease stage in the period between the initial diagnosis and the time of initiation of EGFR-TKI in the first-line setting, index diagnosis was defined as that of diagnosis of the disease stage present at initiation of the EGFR-TKI. In regards to the definitions of primary and secondary (acquired) resistance, the following apply: primary resistance was defined as progressive disease (PD) or stable disease (of less than 6 months duration) as best response while receiving EGFR-TKI in the first-line setting, and secondary resistance was defined as progression of the disease after a period of clinical benefit; i.e., complete response (CR), partial response (PR), or durable stable disease (SD) ( $\geq 6$ months). 
In addition, the progression patterns have been classified as oligoprogression, systemic progression, and central nervous system (CNS) sanctuary PD based on the following definitions: oligoprogression was considered as new sites or regrowth in a maximum of three anatomic sites; systemic progression was defined as multi-site progression, which may include both new metastatic sites as well as regrowth in previously responsive sites of disease; and CNS sanctuary progression was defined as isolated CNS failure, primarily parenchymal brain metastasis, in the absence of systemic progression [34].

\subsection{Statistical Analysis}

Statistical analyses were performed using SAS ${ }^{\circledR}$ v.9.4 (SAS Institute Inc., Cary, NC, USA). The normality of distribution of continuous variables was examined using the Shapiro-Wilk test. Summary statistics of continuous variables are presented as mean (SD) in cases data follow a normal distribution; otherwise, the median (interquartile range; IQR) is presented. Regarding proportions, 95\% Clopper-Pearson confidence intervals (CIs) were calculated.

In the primary endpoint analysis, patients classified as T790M-negative based on their plasma-based liquid biopsy who were found to be T790M-positive according to the results based on the tissue re-biopsy were classified as being positive for T790M, whereas if the results based on the tissue re-biopsy were inconclusive, they were classified as being T790Mnegative, according to their initial plasma-based results. The effect of selected factors of interest on the study's primary outcome (T790M status) was examined using univariable logistic regression models. The following factors were examined: age at the time of biopsy collection upon disease progression in the first-line treatment setting ( $\leq 65$ years versus $>65$ years); smoking status at enrollment (never-smoker versus ever-smoker), sex (female versus male), ECOG performance status (PS) at enrollment (0-1 versus $\geq 2$ ), generation of first-line EGFR-TKI (second versus first), presence of exon19 deletions, L858R mutation, exon 19 deletions and/or L858R mutation, and exon 20 mutation prior to first-line treatment initiation, type of biopsy to determine T790M status (tissue versus plasma), (re)biopsy collection site (site of the primary tumor versus metastatic site), time from EGFR-TKI initiation in the first-line setting to disease progression ( $\geq 10$ versus $<10$ months), time elapsed from first documentation of disease progression in the first-line setting to biopsy collection for EGFR mutation analysis ( $\geq 1$ versus $<1$ month), best response to first-line EGFR-TKI (CR/PR/SD versus PD), and type of resistance to first-line EGFR-TKI therapy (secondary versus primary resistance). All statistical tests were two-sided and were performed at a 0.05 significance level.

\subsection{Sample Size}

The sample size calculation was based on the study's primary endpoint. A sample size of 115 patients (taking into consideration an estimated 15\% drop out/non-evaluable rate) offers a maximum margin of error (minimum precision) of \pm 0.10 , considering the maximum indetermination (i.e., the worst-case proportion estimate of 0.5 ) and a binomial two-sided confidence level of $95 \%$ using the normal approximation method. Sample size determination was performed using the statistical software package SAS v9.4 (SAS Institute, Cary, NC, USA).

\section{Results}

\subsection{Patient Disposition and Characteristics at Enrollment}

A total of 96 eligible patients were consecutively enrolled in this study by 23 hospitalbased oncologists/pneumonologists between 26 July 2017 and 24 September 2019. Of these, 18 patients also attended an optional interim visit that involved tissue re-biopsy (Figure 2). 


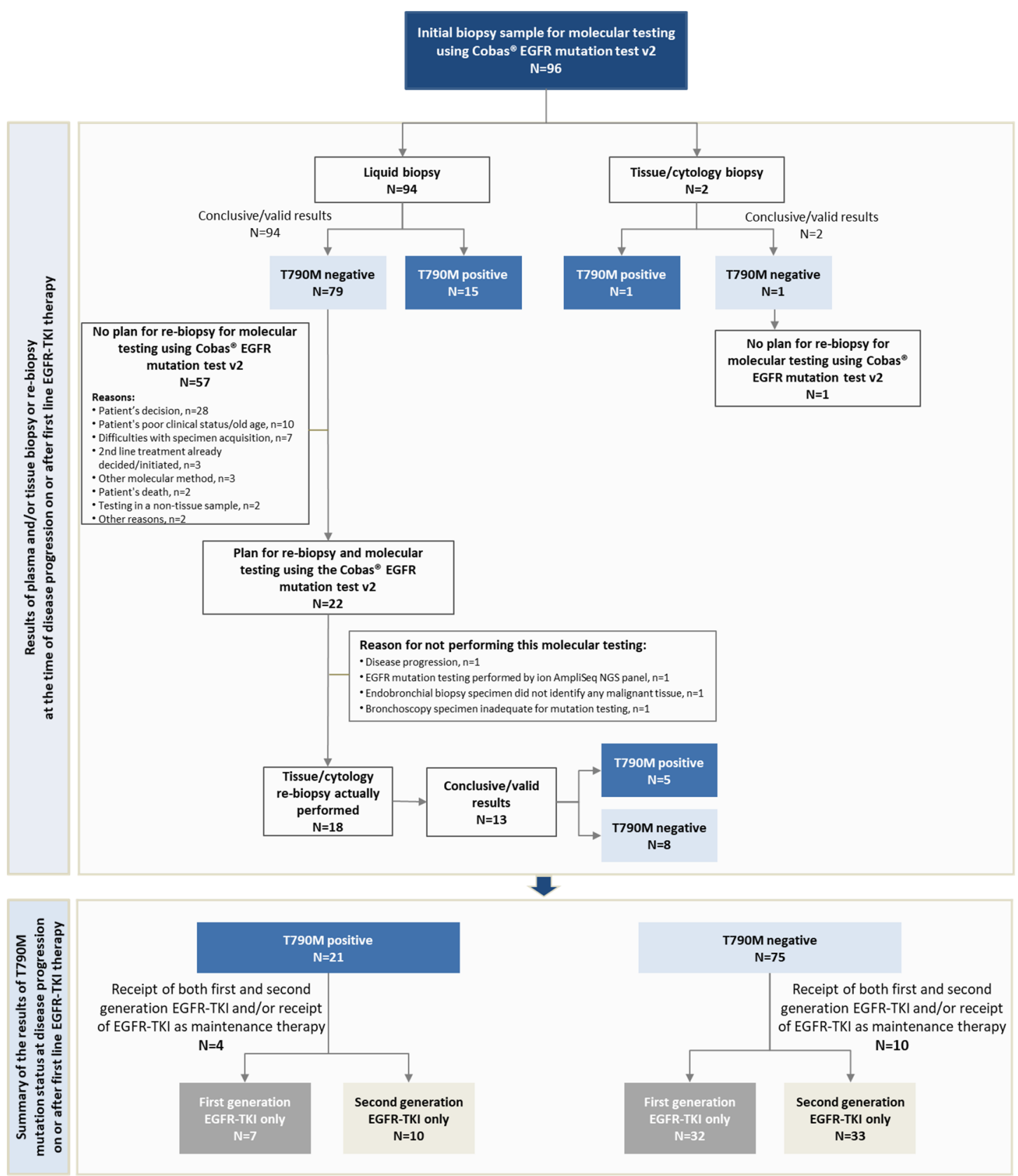

Figure 2. Biopsy and re-biopsy workflow and distribution of patients by T790M status and generation of the EGFR-TKI therapy received in the first-line treatment setting.

All eligible patients were Caucasians and $67.7 \%$ were females. At enrollment, the patients' median age was 67.8 years $(59.4 \%$ were aged $>65$ years), $42.7 \%$ of the patients were ever-smokers, and $83.3 \%$ had an ECOG performance status of $0 / 1$ (Table 1).

\subsection{NSCLC Disease Characteristics at Initial NSCLC Diagnosis, at First-Line EGFR-TKI} Treatment Initiation, and at the Time of Progression in the First-Line Setting

The patients' median age at initial NSCLC diagnosis was 66.8 years, with $82(85.4 \%)$ having been diagnosed with advanced NSCLC (including 75 diagnosed with stage IV disease). The primary tumor was adenocarcinoma in $95.8 \%$ of evaluable patients. At the time of EGFR-TKI treatment initiation in the first-line setting, nine patients $(9.4 \%)$ had locally advanced and $87(90.6 \%)$ had metastatic NSCLC, while a total of 89 patients had metastatic disease at the time of progression in the first-line setting (Table 2). 
Table 1. Patient characteristics at enrollment.

\begin{tabular}{|c|c|}
\hline Patient Enrollment Characteristics & Value (Mean or Median or $\%$ ) \\
\hline Age $(N=96)$, median (IQR), years & $67.8(57.6-74.9)$ \\
\hline$\leq 65$ years, $n(\%)$ & $39(40.6)$ \\
\hline$>65$ and $\leq 75$ years, $n(\%)$ & $33(34.4)$ \\
\hline$>75$ years, $n(\%)$ & $24(25.0)$ \\
\hline Females $(N=96), n(\%)$ & $65(67.7)$ \\
\hline Caucasian $(N=96), n(\%)$ & $96(100.0)$ \\
\hline $\operatorname{BMI}(N=77)$, mean $(\mathrm{SD}), \mathrm{kg} / \mathrm{m}^{2}$ & $26.3(4.8)$ \\
\hline Obese (BMI $\left.\geq 30 \mathrm{~kg} / \mathrm{m}^{2}\right)(N=77), n(\%)$ & $17(22.1)$ \\
\hline \multicolumn{2}{|l|}{ Smoking status $(N=96)$} \\
\hline Former smokers, $n(\%)$ & $33(34.4)$ \\
\hline Pack-years, median (IQR) & $16.0(10.0-40.0)$ \\
\hline Current smokers, $n(\%)$ & $8(8.3)$ \\
\hline Pack-years, median (IQR) & $17.5(11.3-47.5)$ \\
\hline \multicolumn{2}{|l|}{ ECOG performance status $(N=96), n(\%)$} \\
\hline 0 & $51(53.1)$ \\
\hline 1 & $29(30.2)$ \\
\hline 2 & $12(12.5)$ \\
\hline 3 & $4(4.2)$ \\
\hline $\begin{array}{l}\text { Medical/Surgical history and comorbidities } \\
\text { (excluding surgeries for NSCLC) }(N=96), n(\%)\end{array}$ & $51(53.1)$ \\
\hline Comorbidities $(N=96), n(\%)$ & $43(44.8)$ \\
\hline Hypertension, $n(\%)$ & $21(21.9)$ \\
\hline Hypothyroidism, $n(\%)$ & $11(11.5)$ \\
\hline Diabetes mellitus, $n(\%)$ & $10(10.4)$ \\
\hline Dyslipidemia, $n(\%)$ & $10(10.4)$ \\
\hline
\end{tabular}

BMI: body mass index, IQR: interquartile range, NSCLC: non-small cell lung cancer, SD: standard deviation.

Table 2. NSCLC characteristics at initial and index NSCLC diagnosis and at initiation of EGFR-TKI in the first-line setting.

\begin{tabular}{cc}
\hline $\begin{array}{c}\text { Age at initial diagnosis }(N=96), \text { median }(\mathrm{IQR}), \\
\text { years }\end{array}$ & $66.8(55.5-73.4)$ \\
\hline Specimen used for documentation/confirmation of the initial diagnosis $(N=96), n(\%)$ \\
Histological & $69(71.9)$ \\
Cytological & $14(14.6)$ \\
Histological and cytological & $13(13.5)$ \\
\hline NSCLC stage at initial disease diagnosis $(N=96), n(\%)$ \\
I: IB & $1(1.0): 1(1.0)$ \\
II: IIA, IIB & $5(5.2): 4(4.2), 1(1.0)$ \\
III: IIIA, IIIB, IIIC, Locally advanced (unspecified & $15(15.6): 8(8.3), 5(5.1), 1(1.0), 1(1.0)$ \\
stage) & $75(78.1)$ \\
IV & $91(95.8)$ \\
Primary tumor histological classification $(N=95), n(\%)$ \\
Adenocarcinoma & $3(3.2)$ \\
Squamous cell carcinoma & $1(1.1)$ \\
\hline Carcinoma-predominant &
\end{tabular}


Table 2. Cont.

\begin{tabular}{|c|c|}
\hline $\begin{array}{l}\text { Age at index diagnosis with advanced NSCLC } \\
\qquad(N=96) \text {, median (IQR), years }\end{array}$ & $66.8(56.3-73.4)$ \\
\hline $\begin{array}{l}\text { Age at EGFR-TKI treatment initiation }(N=96), \\
\text { median }(\mathrm{IQR}) \text {, years }\end{array}$ & $66.9(56.4-73.5)$ \\
\hline \multicolumn{2}{|c|}{ NSCLC stage at index diagnosis $(N=96), n(\%)$} \\
\hline III: IIIB, IIIC, Locally advanced (unspecified stage) & 9 (9.4): 6 (6.3), 1 (1.0), $2(2.1)$ \\
\hline IV & $87(90.6)$ \\
\hline \multicolumn{2}{|c|}{ Criteria used for NSCLC staging at index diagnosis $(N=96), n(\%)$} \\
\hline AJCC/UICC 6th edition & $1(1.0 \%)$ \\
\hline AJCC/UICC 7th edition & $35(36.5 \%)$ \\
\hline AJCC/UICC 8th edition & $57(59.4 \%)$ \\
\hline Unknown & $3(3.1 \%)$ \\
\hline \multicolumn{2}{|c|}{ Assays used for EGFR mutation testing prior to initiation of first-line EGFR-TKI $(N=96), n(\%)$} \\
\hline cobas $^{\circledR}$ EGFR Mutation Test v2 & $37(38.5)$ \\
\hline Other cobas ${ }^{\circledR}$ tests & $12(12.5)$ \\
\hline Next-generation sequencing & $28(29.2)$ \\
\hline Other assays & $15(15.6)$ \\
\hline Unspecified assay & $4(4.2)$ \\
\hline \multicolumn{2}{|c|}{ Sample used for EGFR mutation testing prior to initiation of first-line EGFR-TKI $(N=96), n(\%)$} \\
\hline Tumor tissue & $80(83.3)$ \\
\hline Cytology sample & $9(9.4)$ \\
\hline Plasma & $7(7.3)$ \\
\hline \multicolumn{2}{|c|}{ EGFR mutations identified prior to initiation of first-line EGFR-TKI $(N=96), n(\%)$} \\
\hline Exon 19 deletion & $56(58.3)$ \\
\hline L858R & $26(27.1)$ \\
\hline Exon 20 insertion & $6(6.3)$ \\
\hline G719X & $5(5.2)$ \\
\hline S768I & $3(3.1)$ \\
\hline L861Q & $2(2.1)$ \\
\hline T790M & $2(2.1)$ \\
\hline $\begin{array}{c}\text { Other mutations (E709-T710>D, R776S, R836C, } \\
\text { V765M) }\end{array}$ & $4(4.2)$ \\
\hline Exon 19 unspecified mutation & $1(1.0)$ \\
\hline
\end{tabular}

Among patients with metastatic disease at the time of initial diagnosis, $24.0 \%(18 / 75)$ had $>6$ metastatic lesions (other than regional lymph nodes). This percentage was about the same among patients with metastatic disease at the time of EGFR-TKI treatment initiation [24.1\% (21/87)], while it increased to $30.7 \%(27 / 88)$ among evaluable patients with metastatic disease at the time of progression in the first-line setting. The most common metastatic sites were bones, pleural effusion, contralateral lung, brain, liver, and extrathoracic lymph nodes at all examined timepoints.

Specifically, at first-line EGFR-TKI initiation, and at disease progression in the first-line setting, $44.8 \%(39 / 87)$, and $50.6 \%$ (45/89) of patients with metastatic disease had metastasis to bones, $17.2 \%(15 / 87)$, and $23.6 \%(21 / 89)$ had metastasis to the liver, and $14.9 \%(13 / 87)$, and $30.3 \%(27 / 89)$, respectively, had metastasis to the brain (Figure 3 ). 


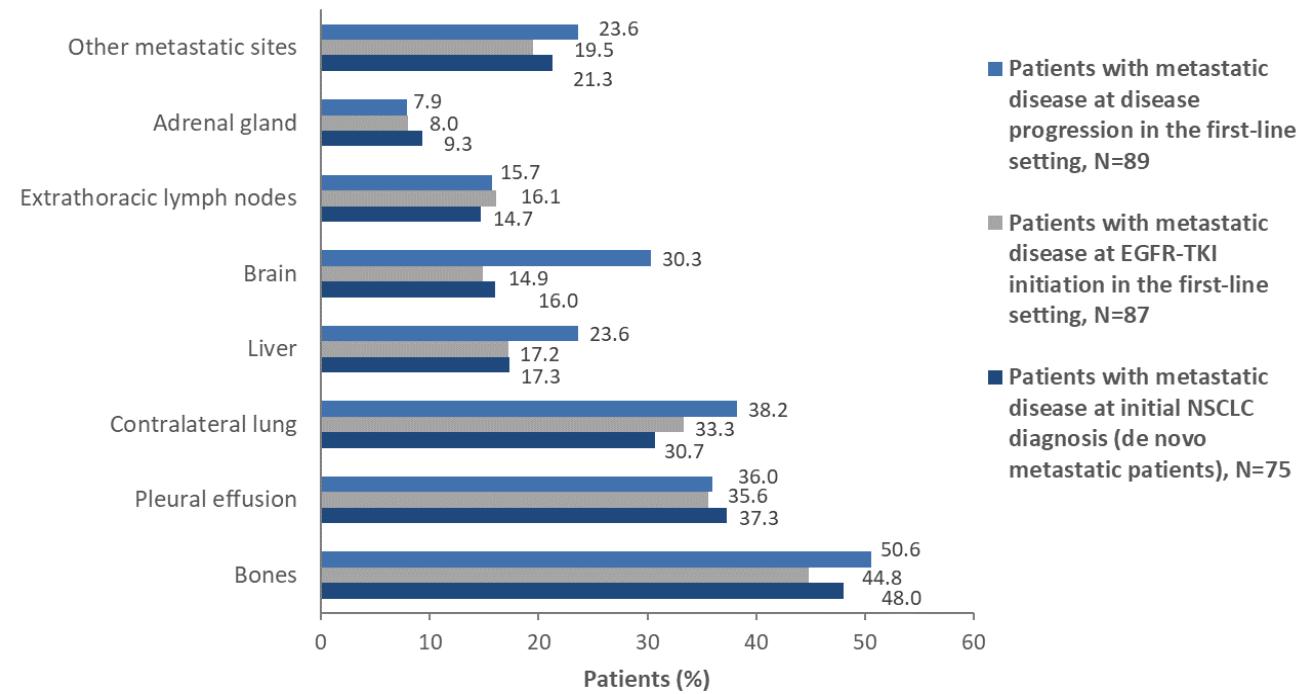

Figure 3. Sites of metastasis at initial diagnosis, EGFR-TKI initiation in the first-line setting, and at disease progression in the first-line setting, in patients of the overall population with metastatic disease.

\subsection{NSCLC Management from Initial Diagnosis until the End of First-Line Treatment for} Advanced Disease

Prior to initiation of first-line treatment with an EGFR-TKI, 38 patients had received surgical and/or pharmacological treatment and/or radiotherapy. Of those, 15 had received chemotherapy as first-line treatment for the index diagnosis prior to initiation of the EGFR-TKI (Table 3). This included six patients who initiated platinum-based combination chemotherapy while waiting for EGFR molecular testing results and who then received EGFR-TKI as first-line therapy, two patients who were initiated on chemotherapy while waiting for EGFR molecular testing results, and who received EGFR-TKI as maintenance therapy, and seven patients for whom the reason for initiating chemotherapy in the firstline setting followed by EGFR-TKI as maintenance therapy was not recorded. First-line treatment for the index advanced disease was initiated at a median (IQR) age of 66.9 (56.4-73.5) years, and included a first-generation EGFR-TKI for 39 patients (40.6\%); a second-generation EGFR-TKI for 43 patients (44.8\%); both a first- and a second- generation EGFR-TKI for five patients (5.2\%), and receipt of a first- and/or second-generation EGFRTKI as maintenance therapy after receipt of platinum-based combination chemotherapy as first-line therapy for nine patients $(9.4 \%)$ (Table 3$)$.

Table 3. NSCLC therapeutic management in the first-line treatment setting and response to treatment.

\begin{tabular}{|c|c|}
\hline First-Line Treatment for the Index NSCLC Diagnosis $(N=96)$ & $n(\%)$ \\
\hline First generation EGFR-TKI without preceding chemotherapy & $35(36.5)$ \\
\hline First generation EGFR-TKI with preceding chemotherapy & $4(4.2)$ \\
\hline Second generation EGFR-TKI without preceding chemotherapy & $41(42.7)$ \\
\hline Second generation EGFR-TKI with preceding chemotherapy & $2(2.1)$ \\
\hline Both a first- and a second-generation EGFR-TKI & $5(5.2)$ \\
\hline $\begin{array}{l}\text { First- and/or second-generation EGFR-TKI as maintenance } \\
\text { therapy after receipt of platinum-based chemotherapy }\end{array}$ & $9(9.4)$ \\
\hline \multicolumn{2}{|l|}{ Best response in the first-line treatment setting, $n(\%)$} \\
\hline $\begin{array}{l}\text { Confirmed and not confirmed } \\
\text { responses }(N=92)\end{array}$ & $\begin{array}{l}\text { Only confirmed } \\
\text { responses }(N=61)\end{array}$ \\
\hline Complete response & $5(8.2)$ \\
\hline Partial response & $21(34.4)$ \\
\hline
\end{tabular}


Table 3. Cont.

\begin{tabular}{ccc}
\hline Stable disease & $25(27.2)$ & $15(24.6)$ \\
Progressive disease & $20(21.7)$ & $20(32.8)$ \\
\hline \multicolumn{3}{c}{ Primary and secondary resistance in the first-line treatment } \\
setting, $n(\%)$ \\
\hline \multicolumn{3}{c}{ Confirmed and not confirmed } \\
responses $(N=92)$ & Only confirmed \\
responses $(N=61)$ \\
\hline Primary resistance & $25(27.2)$ & $22(36.1)$ \\
Secondary resistance & $67(72.8)$ & $39(63.9)$
\end{tabular}

EGFR-TKI: Epidermal growth factor receptor-tyrosine kinase inhibitor, NSCLC: non-small cell lung cancer.

\subsection{Response Rates and Patterns of Disease Progression in the First-Line Treatment Setting}

The ORR during first-line therapy was 51.1\% (47/92) when including both confirmed and unconfirmed responses, while the respective rate including only confirmed responses was $42.6 \%(26 / 61)$ (Table 3). At the time of the first documented disease progression, the EGFR-TKI therapy was ongoing in $85.4 \%$ (82/96) of the patients, temporarily interrupted in $5.2 \%(5 / 96)$, and permanently discontinued in $9.4 \%(9 / 96)$ of the patients.

The median (IQR) time to progression (i.e., time elapsed between initiation of EGFRTKI and the first documented disease progression) was 11.0 (5.6-17.9) months in the overall population, and $11.2(4.8-18.6)$ months in patients who received only a first or second generation EGFR-TKI as first-line therapy (i.e., not including receipt of EGFR-TKI as maintenance therapy), $(n=82)$. Moreover, the median (IQR) time to progression was 11.0 (3.6-17.2) in patients treated with a first-generation EGFR-TKI $(n=39)$, and $11.5(5.8-20.1)$ in patients treated with a second-generation EGFR-TKI $(n=43)$.

Disease progression in the first-line setting was determined using the RECIST v1.1 criteria in $89.6 \%$ (86/96) of the patients or according to physician's assessment based on clinical and/or imaging criteria in $10.4 \%$ (10/96) of the patients. The pattern of progression in the overall population was oligoprogression in $36.5 \%$ (35/96), systemic progression in $42.7 \%$ (41/96), CNS sanctuary progression in 13.5\% (13/96), and clinical progression in the absence of any radiologic evidence of progression (i.e., clinical deterioration of disease-related symptoms) in $7.3 \%(7 / 96)$ of the patients (Figure 4$)$.

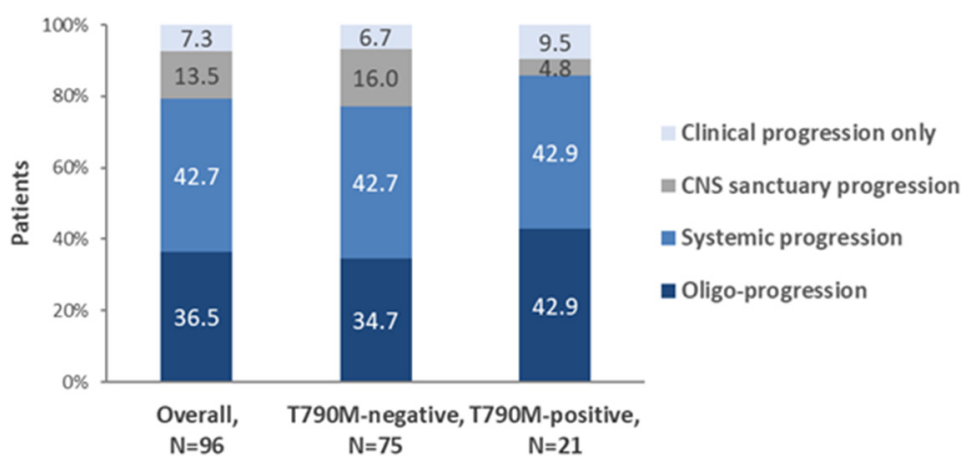

Figure 4. Patterns of disease progression in the first-line treatment setting among the overall population and the T790M-positive and negative subpopulations.

\subsection{EGFR Gene Mutation Profile Prior to EGFR-TKI Treatment Initiation and at Disease Progression in the First-Line Setting}

Prior to EGFR-TKI therapy initiation, exon 19 deletions were detected in $59.4 \%$ of the patients and the L858R mutation in $27.1 \%$; the frequencies of other mutations are presented in Table 2. De novo T790M mutation was identified in $2.1 \%$ of the patients.

At the time of disease progression in the first-line setting, EGFR molecular testing was performed with the cobas ${ }^{\circledR} E G F R$ Mutation test v2 using plasma-based liquid biopsy in 94 
(97.9\%) patients, and a tissue/cytology sample in the remaining two patients $(2.1 \%$; one sample was tissue from the site of the primary tumor and one was pleural effusion). The results of the test were conclusive/valid for all patients during this initial testing (Figure 2). At the time of the first biopsy collection, in plasma or tissue, first-line EGFR-TKI therapy was ongoing in $56.3 \%$, discontinued in $38.5 \%$, and temporarily interrupted in $5.2 \%$ of the patients.

The T790M mutation was detected in 16.0\% (15/94) of plasma biopsies and in one tissue biopsy from the primary tumor; a pleural effusion specimen was negative for T790M. Of the patients found to be negative for T790M (Figure 2), re-biopsy was not planned for the patient for whom molecular testing was performed using a pleural effusion specimen, and for 57 of the 79 patients found negative for T790M by plasma biopsy. Of the remaining 22 patients for whom re-biopsy and molecular testing with cobas ${ }^{\circledR}$ EGFR Mutation test v2 was planned, re-biopsy was actually performed in 18 patients $(22.8 \%)$; re-biopsy involved a tissue sample in 16 cases (from the site of the primary tumor in nine cases and from a metastatic site in seven cases) and cerebrospinal fluid in two cases. The results were conclusive/valid in 13 samples. The T790M mutation was identified in five of the samples, two from a primary tumor site and three from metastatic sites (two from lymph nodes and one from lung metastasis). Thus, taking into consideration the results of re-biopsy a total of 21 patients were found to be positive for the T790M-mutation, and the remaining 75 patients were classified as being T790M-negative (Figure 2). The respective T790Mpositive and T790M-negative rates were 21.9\% (95\% CI: 14.1-31.5) and 78.1\% (95\% CI: 68.5-85.9).

Among patients who underwent plasma-based molecular testing, exon 19 deletions were identified in $29.8 \%(28 / 94)$, the L858R mutation in $16.0 \%$ (15/94), and the T790M mutation in $16.0 \%$ (15/94) of the patients. Among the two patients whose initial molecular testing was performed in a tissue sample, exon 19 deletions were identified in $100.0 \%(2 / 2)$ and the T790M mutation in 50.0\% (1/2). In the overall population, according to both the initial biopsy and the re-biopsy results, the frequencies of exon 19 deletions, the L858R, and the T790M mutations were 30.0\% (30/96), 16.7\% (16/96), and 21.9\% (21/96), respectively. The patterns of the EGFR mutations identified during the initial cobas EGFR Mutation test v2 using plasma biopsy $(n=94)$, during the initial testing with tissue biopsy $(n=2)$, and in the overall population taking into consideration the conclusive/valid results of molecular testing during re-biopsy and the results of the initial biopsy for all other patients are presented in Figure 5 (panels A, C and E, respectively). Among the 21 T790M-positive patients, the most frequently co-occurring mutations were exon 19 deletions $(61.9 \% ; n=13)$, L858R $(28.6 \% ; n=6)$, and exon 20 insertions $(9.5 \% ; n=2)$. Interestingly, lower rates of mutations were identified among the 75 T790M-negative patients, with exon 19 deletions again being the most frequently identified $(22.7 \% ; n=17)$, followed by L858R $(13.3 \%$; $n=10)$ and G719X $(4.0 \% ; n=3)$. The patterns of co-occurring mutations at initial molecular testing using a plasma specimen, at initial testing using a tissue/cytology specimen, and overall using both the molecular test results of the initial biopsy and those of the re-biopsy are displayed in Figure 5 (panels B, D, and F). 
A

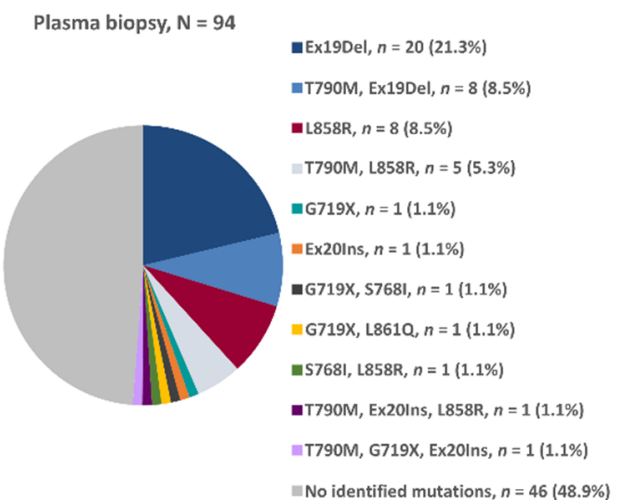

c

Tissue/cytology biopsy, $\mathrm{N}=\mathbf{2}$

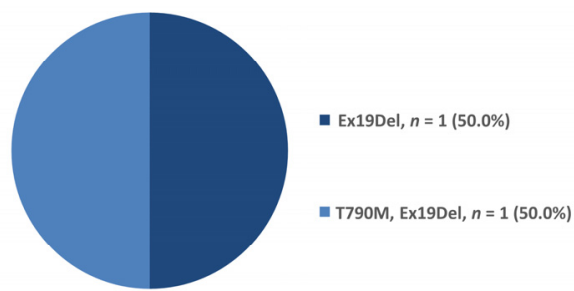

E Plasma biopsy \& Tissue biopsy/re-biopsy, $\mathrm{N}=96$

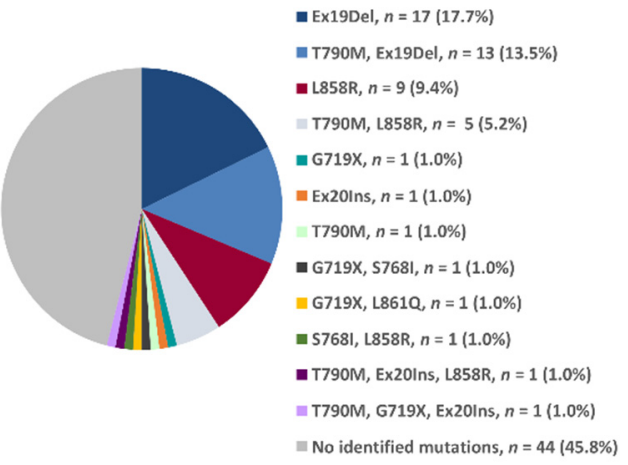

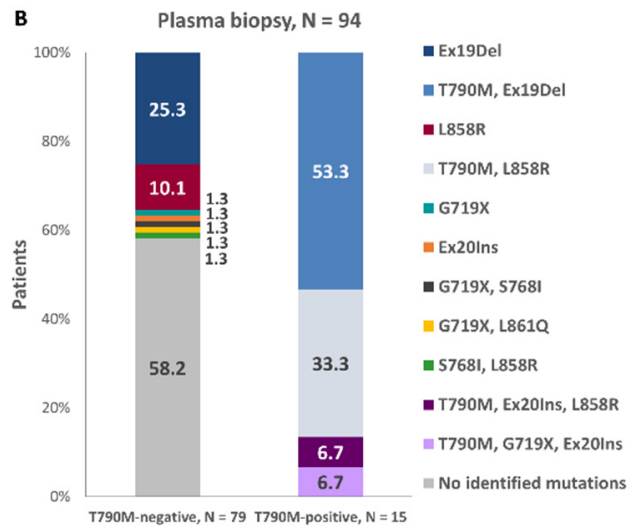

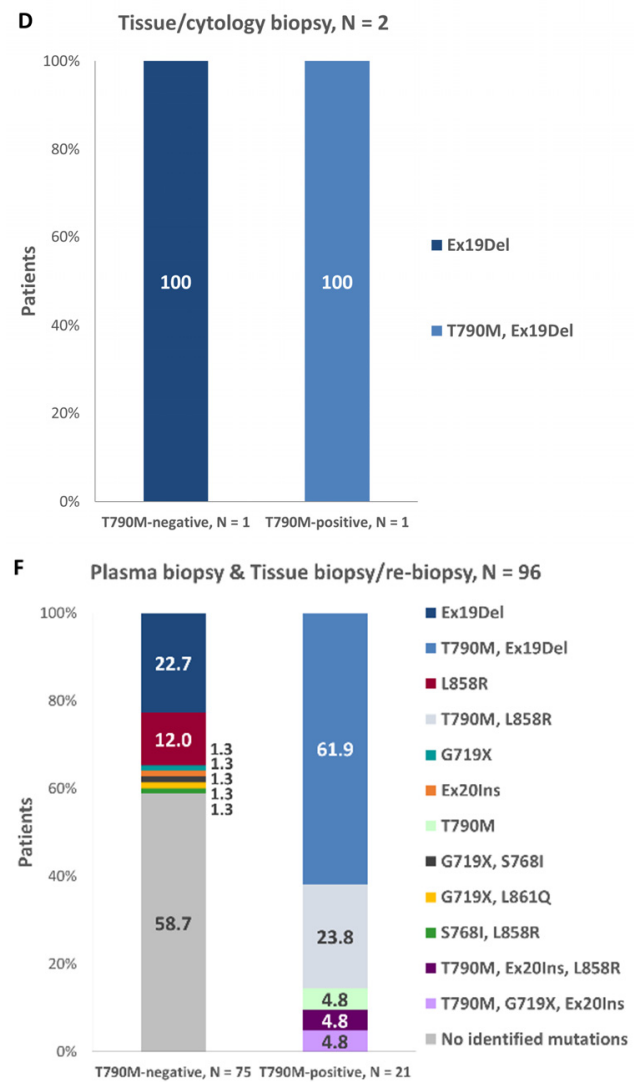

Figure 5. Mutations identified by cobas ${ }^{\circledR}$ EGFR Mutation Test v2 during the initial plasma biopsy (A,B), initial tissue/cytology biopsy (C,D) and the initial plasma biopsy and the initial tissue biopsy or the re-biopsy (E,F), in the overall population (A,C,E) and the T790M-positive and-negative subpopulations (B,D,F). Ex19Del: exon 19 deletion; Ex20Ins: exon 20 insertion.

The median (IQR) time from first documentation of disease progression to collection of the biopsy specimen with a positive T790M result (whether this was the initial plasma/tissue/cytology biopsy or the tissue/cytology re-biopsy sample), or to the initial biopsy with a negative result (in cases that a re-biopsy was not performed or that the re-biopsy confirmed the negative results) was $0.6(0.2-1.4)$ months.

The mutation patterns prior to initiation of EGFR-TKI in the first-line treatment setting and their shift at the time of progression in the first-line setting among patients identified to be T790M-positive at progression are displayed in Table 4. For 18 of the 21 patients the only identified change included acquisition of the T790M. 
Table 4. EGFR mutation profile of T790M positive patients at the time of progression on or after first-line EGFR-TKI prior to first-line EGFR-TKI initiation and at disease progression on or after first-line EGFR-TKI therapy.

\begin{tabular}{cc}
\hline Prior to First-Line EGFR-TKI Initiation & $\begin{array}{c}\text { at Disease Progression on or after } \\
\text { First-Line EGFR-TKI }\end{array}$ \\
\hline Exon 19 deletion, $n=13$ & T790M, Exon 19 deletion, $n=12$ \\
L858R, $n=5$ & T790M, $n=1$ \\
\hline G719X, $n=1$ & T790M, L858R, $n=5$ \\
Exon 20 insertion, L858R, $n=1$ & T790M, Ex19X, Exon 20 insertion, $n=1$ \\
T790M, Exon19 unspecified mutation, $n=1$ & T790M, Exon 19 deletion, $n=1$ \\
\hline
\end{tabular}
EGFR-TKI: Epidermal growth factor receptor-tyrosine kinase inhibitor.

3.6. T790M-Mediated Primary and Secondary Resistance Rates to First-Line EGFR-TKI and Patterns of Progression in T790M-Positive and T790M-Negative Patients

The EGFR-T790M mediated primary and secondary resistance rates were $8.0 \%(2 / 25)$ and $28.4 \%(19 / 67)$ when examining both confirmed and unconfirmed responses, while they were $4.5 \%(1 / 22)$ and $33.3 \%(13 / 39)$ when examining only confirmed responses. The patterns of progression in the first-line treatment setting among the T790M-positive and T790M-negative subpopulations are presented in Figure 4.

\subsection{Association of Patient and Clinicopathological Characteristics with EGFR-T790M Status}

Patient and clinicopathological characteristics in T790M-positive and T790M-negative patients presented in Table 5 were examined as to their association with T790M mutation status (Table 5). Of the examined factors, patients with ECOG performance status of $0-1$ at enrollment compared to those with ECOG performance status $>2$ were less likely to be T790M-positive $(p=0.026)$, while patients with a longer time to disease progression following initiation of EGFR-TKI were more likely to be T790M-positive $(p=0.027)$ (Table 5).

\subsection{Deaths and Study Withdrawal}

Until the data cut-off date in the context of this interim analysis, $20(20.9 \%)$ patients had died. In particular, 14 deaths occurred prior to initiation of second-line treatment and six after initiation of second-line treatment in the absence of documented disease progression in the second-line setting. In addition, 18 patients $(18.8 \%)$ were withdrawn from the study due to disease progression in the second-line setting, and one patient was lost-to-follow-up. Therefore, in total 39 patients $(40.6 \%$ ) had discontinued study participation by the interim data cut-off date. 
Table 5. Patient and clinicopathological characteristics according to the T790M mutation status.

\begin{tabular}{|c|c|c|c|c|}
\hline Patient Characteristics & & $\begin{array}{l}\text { T790M-Positive } \\
n(\%)\end{array}$ & $\begin{array}{l}\text { T790M-Negative } \\
n(\%)\end{array}$ & $p$-Value \\
\hline \multirow{4}{*}{$\begin{array}{l}\text { Age at the time of biopsy collection upon disease progression on or after first-line EGFR-TKI } \\
\text { treatment }(N=96) \\
\text { Smoking status at enrollment }(N=96)\end{array}$} & $>65$ years & $13(61.9)$ & $44(58.7)$ & \multirow{2}{*}{0.790} \\
\hline & $\leq 65$ years & $8(38.1)$ & $31(41.3)$ & \\
\hline & Ever-smoker & $10(47.6)$ & $31(41.3)$ & \multirow{2}{*}{0.607} \\
\hline & Never-smoker & $11(52.4)$ & $44(58.7)$ & \\
\hline \multirow[t]{2}{*}{$\operatorname{Sex}(N=96)$} & Male & $5(23.8)$ & $26(34.7)$ & \multirow[t]{2}{*}{0.350} \\
\hline & Female & $16(76.2)$ & $49(65.3)$ & \\
\hline ECOG performance status at enrollment $(N=96)$ & $\overline{0-1}$ & $14(66.7)$ & $66(88.0)$ & 0.026 \\
\hline \multirow{2}{*}{ Generation of first-line EGFRI-TKI $(N=82)^{\dagger}$} & First-generation & $7(41.2)$ & $32(49.2)$ & \multirow[t]{2}{*}{0.555} \\
\hline & Second-generation & $10(58.8)$ & $33(50.8)$ & \\
\hline \multirow{2}{*}{ Exon 19 deletion prior to initiation of first-line EGFR-TKI $(N=96)$} & No & $8(38.1)$ & $32(42.7)$ & \multirow[t]{2}{*}{0.707} \\
\hline & Yes & $13(61.9)$ & $43(57.3)$ & \\
\hline \multirow{2}{*}{ L858R mutation prior to initiation of first-line EGFR-TKI $(N=96)$} & No & $15(71.4)$ & $55(73.3)$ & \multirow[t]{2}{*}{0.862} \\
\hline & Yes & $6(28.6)$ & $20(26.7)$ & \\
\hline Exon 19 deletion and/or L858R mutation prior to initiation of first-line EGFR-TKI $(N=96)$ & No & $2(9.5)$ & $12(16.0)$ & 0.463 \\
\hline Exon 20 insertion prior to initiation of first-line EGFR-TKI $(N=96)$ & Yes & $2(9.5)$ & $10(13.3)$ & 0.643 \\
\hline \multirow{2}{*}{ Type of biopsy to determine T790M status $(N=96)$} & Plasma-based liquid & $15(71.4)$ & $74(98.7)$ & \multirow[t]{2}{*}{0.002} \\
\hline & Tissue & $6(28.6)$ & $1(1.3)$ & \\
\hline \multirow[t]{2}{*}{ Tissue biopsy / re-biopsy collection site $(N=17)$} & Metastatic site & $3(50.0)$ & $4(36.4)$ & \multirow[t]{2}{*}{0.587} \\
\hline & $\begin{array}{l}\text { Site of the primary } \\
\text { tumor }\end{array}$ & $3(50.0)$ & $7(63.6)$ & \\
\hline \multirow{2}{*}{$\begin{array}{c}\text { Time elapsed between EGFR-TKI initiation in the first-line setting and first documented } \\
\text { disease progression }(N=82)^{+}\end{array}$} & $<10$ months & $3(17.6)$ & $32(49.2)$ & \multirow[t]{2}{*}{0.027} \\
\hline & $\geq 10$ months & $14(82.4)$ & $33(50.8)$ & \\
\hline \multirow{2}{*}{$\begin{array}{l}\text { Time from first documentation of disease progression in the first-line setting to biopsy } \\
\text { collection for } E G F R \text { mutation analysis with the cobas }{ }^{\circledR} \text { EGFR Mutation Test v2 }(N=96)\end{array}$} & $<1$ month & $11(52.4)$ & $53(70.7)$ & \multirow[t]{2}{*}{0.121} \\
\hline & $\geq 1$ month & $10(47.6)$ & $22(29.3)$ & \\
\hline \multirow{2}{*}{$\begin{array}{l}\text { Best response to first-line EGFR-TKI based on confirmed and not confirmed responses } \\
\qquad(N=92)\end{array}$} & PD & $1(4.8)$ & $19(26.8)$ & \multirow[t]{2}{*}{0.060} \\
\hline & $\mathrm{CR} / \mathrm{PR} / \mathrm{SD}$ & $20(95.2)$ & $52(73.2)$ & \\
\hline \multirow{2}{*}{$\begin{array}{l}\text { Type of resistance to first-line EGFR-TKI based on confirmed and not confirmed responses } \\
\qquad(N=92)\end{array}$} & Primary resistance & $2(9.5)$ & $23(32.4)$ & \multirow[t]{2}{*}{0.054} \\
\hline & Secondary resistance & $19(90.5)$ & $48(67.6)$ & \\
\hline
\end{tabular}

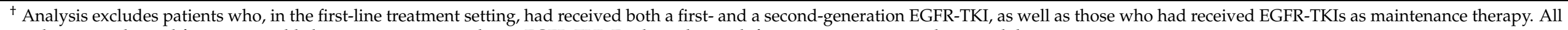
$p$-values were derived from univariable logistic regression analyses. EGFR-TKI: Epidermal growth factor receptor-tyrosine kinase inhibitor. 


\section{Discussion}

The 'LUNGFUL' study provides real-world evidence from routine care clinical settings in Greece on the frequency of EGFR mutations, focusing on T790M, in patients with EGFRmutated advanced NSCLC who have progressed in the first-line EGFR-TKI (1st or 2nd generation) treatment setting. In this study, molecular testing was performed in tissue and/or plasma biopsy samples using the cobas ${ }^{\circledR}$ EGFR Mutation Test v2.

Prior to initiation of EGFR-TKI therapy, exon 19 deletions and the L858R substitution were the most frequently detected mutations, while the de novo T790M substitution was detected in $2.1 \%$ of the patients with EGFR mutations, in agreement with the range $(1.0-2.2 \%)$ reported by other studies [35-37], including a retrospective study by the Hellenic Co-operative Oncology Group [38]. At disease progression on or after first-line EGFR-TKI therapy, $21.9 \%$ of the patients were T790M-positive. The rate observed in 'LUNGFUL' is lower than that reported in other international studies [20,21,39-42], but is higher than the $16 \%$ rate obtained by cobas in liquid biopsies in another study from Greece, which reported results both from next generation sequencing and from cobas analysis [43]. T790M positivity rate in our study was similar to that of a recent study performed in Korea, with positivity rate of $23 \%$, but with the main difference that this study was conducted in Asian population [44]. The incidence of T790M among NSCLC patients who progressed upon EGFR-TKI as first-line therapy reported by other studies ranges from $36 \%$ to $70 \%$, not largely differing between patients who have previously received a first- or secondgeneration EGFR-TKI $[20,21,24,39,40,42,43]$. Although the observed differences could reflect real variation among the populations analyzed, the applied method of molecular testing could also account for some of the discrepancies, as the sensitivity and specificity of the methods vary [45]. Nonetheless, in a combined analysis of AURA Extension and AURA2, which similarly to the present study utilized cobas ${ }^{\circledR}$ methodology for detection of EGFR mutations, the pooled T790M rate was $63 \%$, which is much higher than that in our study [46]. It is noted that in this pooled analysis, the rate of T790M positivity did not differ between Asian and non-Asian patients, which suggests that the source of the variation between this study and ours is likely not the difference in ethnic background, and could at least partly be attributable to different tumor burden and number of prior treatment lines received by the patients, as all patients in our study had received EGFR-TKI in the first-line setting, whereas in the AURA trials patients could have received more than one prior line of therapy [46]. On the other hand, both in 'LUNGFUL' and in the pooled analysis of AURA extension and AURA2, the generation of the immediately prior EGFR-TKI was not shown to be associated with the T790M rate [46].

At disease progression in the first-line setting, the co-occurrence of T790M mutation with exon 19 deletion in our study was almost 2.2-fold higher than the co-occurrence of T790M with L858R (61.9 versus 28.6\%). A higher proportion of co-occurring exon 19 deletions than L858R mutation in T790M-positive patients has been reported elsewhere [42,43], with the respective rates being $67.5 \%$ and $29.5 \%$ in the pooled analysis of the AURA extension and AURA2 trials [46]. Importantly, in our study, the rate of detection of exon 19 deletions was higher than that of the L858R substitution in T790M-positive and T790Mnegative patients alike. This finding is similar to that presented in a 2019 Hellenic national conference from a series of 403 unique plasma samples examined by cobas testing (I. Boukovinas unpublished data from the 11th Training Seminar in Clinical Oncology, held in November 2019). In particular, the T790M detection rate in these 403 samples was $14 \%$. Moreover, exon 19 deletions were detected in $68.5 \%$ of T790M-positve and in $19.5 \%$ of T790M-negative patients, while L858R mutation was detected in $7.4 \%$ and $6.1 \%$ of T790M-positive and T790M-negative patients, respectively. A higher frequency of exon 19 deletions compared to the L858R mutation among Caucasian populations has been consistently reported [46].

It also of interest to highlight that although $95.2 \%$ (20/21) of T790M positive patients had co-occurring mutations, only $41.3 \%$ (31/75) of T790M negative patients carried activating mutations. Among other reasons, this finding may be explained by a potential higher 
rate of incomplete tumor ctDNA shedding among T790M-negative patients, a mechanism also accounting for false negative T790M results [47].

Furthermore, previous studies have also reported a higher rate of T790M positivity in patients with initial exon 19 deletion (range: 38-63\%), than in patients with pre-existing L858R mutations (range: 26-43\%) [42,48]. In 'LUNGFUL', the frequencies of T790M were about $23.0 \%$ both in patients with exon 19 deletions and in those with the L858R mutation prior to initiation of EGFR-TKI therapy, with neither of the two factors shown to predict T790M status. Conversely, a significant association was observed between T790M status and type of biopsy. Previous studies comparing the prevalence of T790M between cytology and tissue samples have revealed no significant differences [42,48]. Regarding the concordance rates between tumor tissue and plasma using cobas, rates of $64 \%$ to $79 \%$ have been reported $[49,50]$. In our patient population, of the 13 cases with negative T790M results using a plasma biopsy, $8(61.5 \%)$ were also shown to be negative using a tissue sample, while the remaining five cases were found to be positive.

Of note, in 46 samples no mutations were detected after progression, a number relatively high. As shown in a recent exploratory ctDNA analysis from patients enrolled in the AURA 3 study, almost $25 \%$ of patients treated with osimertinib were defined as non-shedders as they were not found positive for any of the three main EGFR mutations (T790M, del19, L858R) [51]. While there were no clear associations of the EGFR tumor shedding status with sex, race, smoking status and performance status according to Eastern Cooperative Oncology Group (ECOG), an association with the baseline tumor target lesion size has been reported. In addition it has been previously reported that the detection of EGFR mutations in both plasma and tissue samples was associated with metastatic status [49]. More specifically, the presence of extrathoracic disease(M1b) was associated with the detection of EGFR mutations in plasma with statistical significance when compared to intrathoracic $(\mathrm{M} 1 \mathrm{a} / \mathrm{M} 0)$ disease. In the above context and taking into consideration that i. all labs participating in the LUNGFUL trial for the detection of T790M in plasma, using cobas EGFR Mutation Test v. 2 have been successfully participated in a robin trial for the detection of different EGFR mutations in different concentrations in plasma [52] and that ii. cfDNA BCTs were used to retain both the integrity of the cfDNA population and the stability of blood cells preventing dilution of ctDNA with wild-type genomic DNA, preanalytic and analytic issues may not account for the inability to identify any mutation in the plasma of 46 patients.

Rather this should be attributed to either "non shedder" status or disease burden status as explained above. It is generally accepted that plasma-based biopsy helps circumvent some of the challenges of re-biopsy, stemming from procedure invasiveness and heterogeneity of the tumor tissue $[28,29,45]$. In fact in our study, while EGFR mutation testing at the time of diagnosis in the context of first-line treatment initiation in the advanced setting had been performed using a sample from tissue biopsy in more than $80 \%$ of the patients, this proportion at the time of re-biopsy on or after progression in the first-line treatment setting was only $1 \%$. Moreover, of the patients who were negative for T790M based on liquid biopsy, and for whom guidelines [3] recommend a tissue re-biopsy, such a biopsy was not planned for $72 \%$, with patient unwillingness, poor clinical status/old age, and difficulties with specimen acquisition being the main reasons. Similarly, in a study conducted in China, the rate of non-performance of re-biopsy at the time of progression after receipt of a first-generation EGFR-TKI was rather high (about 47\%). The main reasons for not performing re-biopsy included lesion sizes and/or locations unsuitable for biopsy, poor health, older age or severe comorbidity, and patient unwillingness [53]. These constraints of tissue re-biopsy may reflect logistic and infrastructure hurdles in hospitals and merit further actions from the healthcare community, as plasma biopsies can give false-negative results, so patients who could potentially benefit from treatment with third-generation TKIs might be missed [54]. Based on findings from AURA2 and AURA3 studies, specificity is $79 \%$ for the T790M, whereas it is not an issue for the activating EGFR mutations. However, 
liquid biopsy is a valid option to consider when re-biopsy is not an option for the treating physicians [55].

With respect to disease progression, compared to T790M-negative patients, T790Mpositive patients exhibited higher oligoprogression rates ( $42.9 \%$ versus $34.7 \%$ ) and lower CNS sanctuary progression rates $(4.8 \%$ versus $16.0 \%)$, while rates of systemic progression ( $42.9 \%$ versus $42.7 \%$ ) were about the same. In a previous report, the T790M positive rate was significantly higher in patients with local progression compared to those with gradual progression and dramatic progression [41]. Moreover in 'LUNGFUL', the median time to progression since initiation of EGFR-TKI in the first-line setting was 11.0 months in the overall population, being similar among patients treated with only a first-generation and only a second-generation EGFR-TKI (11.0 versus 11.5 months), and aligning with findings from the phase III trials of first and second generation EGFR-TKIs [4-8,11-13,23]. Logistic regression analysis revealed a significant association of T790M positive mutation status with the time elapsed between EGFR-TKI initiation in the first-line setting and the first documented disease progression. This observation is similar to the finding of a previous study that patients with longer duration of EGFR-TKI treatment had a higher T790M positive rate [56], but differs from other studies, which showed no such association [57,58]. Moreover, a longer period of EGFR-TKI treatment continuation post disease progression has also been shown to be associated with a higher rate of T790M positivity [57]. Identifying predictors of T790M positivity post-progression in the first-line setting is a field of active research as treatment-decision making in the second-line setting largely depends on T790M status. The results of our final analysis will elaborate on the treatment management strategies employed in the second-line setting depending on the patients' patterns of progression, prior therapy, patterns of metastasis, and T790M mutation status.

The main limitations of this study are attributed to its observational design and primarily include inherent patient selection and information bias, the latter of which is considered to be small due to the low missing data rates. In order to mitigate potential patient selection bias, physicians were requested to consecutively enroll the first eligible patients (based on the site-specific target) attending their clinic over the pre-specified study recruitment period. In addition, the Investigators' decision to perform EGFR molecular testing post-disease progression using the cobas ${ }^{\circledR}$ EGFR Mutation Test v2 was based on current medical practice and preceded the consideration of the patient's eligibility for enrollment into the study. Moreover, there may be information bias regarding EGFR mutation testing at initial diagnosis, at both an inter- and intra-patient level, since testing was performed at several independent laboratories, employing different assays according to routine practice. Thus, any inferences that may be drawn regarding changes in the EGFR mutational profile between the start EGFR-TKI treatment and the time of progression in the first-line treatment setting should take into consideration this source of potential variability. This source of bias does not apply for testing performed at the time or after the first PD, since a uniform test approved by the FDA was used, pre-analytical factors were the same and a pilot plasma-ctDNA ring trial for the cobas ${ }^{\circledR}$ EGFR Mutation Test in clinical diagnostic laboratories performed in 2018 in Greece, showed that genotyping results were satisfactory [52]. Furthermore, while a total of 96 patients were evaluable for the study's primary objective meeting the planned study size, a very high proportion of patients $(84 \%)$-identified to be negative by molecular testing performed in a plasma sample-did not undergo re-biopsy or had inconclusive results. This may have resulted in an underestimation of the study's primary objective pertaining to the frequency of T790M positivity, as supported by the fact that among patients found T790M-negative based on plasma biopsies who underwent tissue re-biopsy, the percentage of T790M positivity was as high as $38 \%$. It is noted that it was within the study's aim to record the re-testing frequency in the routine care in Greece.

This study was designed in 2016, when osimertinib was only approved by EMA as a 2nd line treatment for patients harboring the resistance mutation T790M or as a 1st line treatment for patients expressing $7790 \mathrm{M}$ as de novo mutation. At the time being, after 
FLAURA's study data release, osimertinib is recommended by ESMO guidelines, as 1st line treatment in patients expressing sensitizing mutation of EGFR and patient expressing T790M as de novo mutation with the score [I, A; MBCS score v1.1 score: 4]. This treatment algorithm evolvement does not affect the primary objective of our study, which is to assess the frequency of T790M mutation in the real-world Greek population, regarding patients receiving 1st line treatment with 1st or 2nd generation TKIs [3,9].

Regarding external validity, the study population was enrolled from sites located in five of the 13 administrative regions of Greece, which are home to $67 \%$ of the overall Greek population, aiding the geographic diversity of the sites and generalizability of the findings. Representativeness was also facilitated by the enrollment of patients by 23 physicians treating patients with lung cancer in the primary care hospital outpatient or private practice setting, accounting for variations in medical practice paradigms.

\section{Conclusions}

In the real-world clinical setting in Greece, a 21.9\% T790M positivity rate was detected, based on cobas ${ }^{\circledR}$ molecular testing in plasma and/or tissue biopsy at the time of progression in the first-line setting with first- and second-generation EGFR-TKIs. The rate of testing in tissue/cytology samples was very low, with only 15 results based on tissue/cytology samples. The T790M positive rate was lower based on results from plasma (16.0\%) than from tissue/cytology (40.0\%) biopsies. The overall rate (which mainly reflects the rate in plasma biopsies) is lower compared to previous reports. T790M positivity was shown to be similar among patients who had previously received a first- or second-generation EGFR-TKI, while it was higher in those with a longer period between treatment initiation and disease progression in the first-line setting. Presence of exon 19 deletions and L858R mutations prior to initiation of first-line treatment did not predict acquisition of T790M. Upon disease progression in the first-line setting, re-biopsy included a plasma sample in nearly all patients, while among those who tested negative in their plasma sample, fewer than one in four underwent a tissue re-biopsy. This underscores the challenges of performing tissue re-biopsy in routine care settings, which can lead to patients not considered eligible for certain therapies from which they can benefit, and merits further actions from the healthcare community.

Author Contributions: Contributions: (I) Conception and design: A.S., F.P., Z.P.; (II) Administrative support: A.S., F.P., Z.P., A.N.; (III) Provision of study materials or patients: G.M., A.K., A.B., D.M., E.S., E.G.F., H.L., P.K., E.A., M.V.K., G.P., S.L., M.E.F., E.-I.A.P., A.S., F.P., Z.P., A.N., K.N.S.; (IV) Collection and assembly of data: G.M., A.K., A.B., D.M., E.S., E.G.F., H.L., P.K., E.A., M.V.K., G.P., S.L., M.E.F., E.-I.A.P., K.N.S.; (V) Data analysis and interpretation: G.M., A.K., A.B., D.M., E.S., E.G.F., H.L., P.K., E.A., M.V.K., G.P., S.L., M.E.F., E.-I.A.P., A.S., F.P., Z.P., A.N., K.N.S.; (VI) Manuscript writing: G.M., A.K., A.B., D.M., E.S., E.G.F., H.L., P.K., E.A., M.V.K., G.P., S.L., M.E.F., E.-I.A.P., A.S., F.P., Z.P., A.N., K.N.S.; (VII) Final approval of manuscript: G.M., A.K., A.B., D.M., E.S., E.G.F., H.L., P.K., E.A., M.V.K., G.P., S.L., M.E.F., E.-I.A.P., A.S., F.P., Z.P., A.N., K.N.S. All authors have read and agreed to the published version of the manuscript.

Funding: This work was supported and funded by AstraZeneca.

Institutional Review Board Statement: The study was conducted according to the guidelines of the Declaration of Helsinki, and approved by the Institutional Review Board (Scientific Council and/or Board of Directors) of the participating hospital sites (protocol code D133FR00126).

Informed Consent Statement: Informed consent was obtained from all subjects involved in the study.

Data Availability Statement: The data presented in this study are contained within the article. The data are not publicly available due to restrictions that apply to the availability of the data (e.g., privacy or ethical). Datasets from this study may be available upon request from the corresponding author and provided upon approval from the sponsor and in accordance with data privacy and ethical provisions. 
Acknowledgments: The authors are much obliged to many colleagues who contributed by their engagement to the success of this study: Nikolaos Koulouris, Ioannis Xanthakis, Sofia Mpaka, Ioannis Boukovinas, Charalampos Andreadis, Aggeliki Rapti, Dimitrios Kassarakis and Charisios Karanikiotis. The authors would also like to thank Andriana Papakonstantinou, Agoritsa Bismpiroula, and Panagiota Karagianni (Qualitis Ltd., Athens, Greece) for the statistical analysis, writing and English editing.

Conflicts of Interest: All authors have completed the ICMJE uniform disclosure form; G.M. reports personal fees from AstraZeneca, during the conduct of the study. A.K reports grants from AstraZeneca, during the conduct of the study. E.G.F. reports grants from AstraZeneca, during the conduct of the study; non-financial support from Roche, non-financial support from Faran, personal fees and non-financial support from WinMedica, non-financial support from Aenorasis, non-financial support from Pfizer, non-financial support from Sanofi, outside the submitted work. H.L. reports personal fees from Bristol Myers Squibb, personal fees from Roche, personal fees from Merck Sharp \& Dohme, personal fees from Amgen, personal fees from Pfizer, personal fees from Novartis, personal fees from AstraZeneca, personal fees from Takeda, personal fees from Merck, personal fees from Abbvie, personal fees from Boehringer Ingelheim, personal fees from Lilly, personal fees from Parexel International, personal fees from Qualitis, personal fees from Pharmaceutical Product Development, outside the submitted work. G.P. reports research grant from AstraZeneca, outside the submitted work. A.S., F.P., Z.P. and A.N. belong to the staff of AstraZeneca. The other authors declare no conflict of interest.

\section{References}

1. Global Cancer Observatory: Cancer Today; International Agency for Research on Cancer. Estimated Number of New Cases in 2018. Available online: http:/ /gco.iarc.fr/ (accessed on 5 May 2020).

2. World Cancer Research Fund International. Lung Cancer Statistics. Available online: https://www.wcrf.org/dietandcancer/ cancer-trends/lung-cancer-statistics (accessed on 5 May 2020).

3. Planchard, D.; Popat, S.; Kerr, K.; Novello, S.; Smit, E.F.; Faivre-Finn, C.; Mok, T.S.; Reck, M.; Van Schil, P.E.; Hellmann, M.D.; et al Metastatic non-small cell lung cancer: ESMO Clinical Practice Guidelines for diagnosis, treatment and follow-up. Ann. Oncol. 2018, 29, iv192-iv237. [CrossRef]

4. Inoue, A.; Kobayashi, K.; Maemondo, M.; Sugawara, S.; Oizumi, S.; Isobe, H.; Gemma, A.; Harada, M.; Yoshizawa, H.; Kinoshita, I.; et al. Updated overall survival results from a randomized phase III trial comparing gefitinib with carboplatin-paclitaxel for chemo-naive non-small cell lung cancer with sensitive EGFR gene mutations (NEJ002). Ann. Oncol. 2013, 24, 54-59. [CrossRef]

5. Maemondo, M.; Inoue, A.; Kobayashi, K.; Sugawara, S.; Oizumi, S.; Isobe, H.; Gemma, A.; Harada, M.; Yoshizawa, H.; Kinoshita, I.; et al. Gefitinib or chemotherapy for non-small-cell lung cancer with mutated EGFR. N. Engl. J. Med. 2010, 362, 2380-2388. [CrossRef] [PubMed]

6. Mitsudomi, T.; Morita, S.; Yatabe, Y.; Negoro, S.; Okamoto, I.; Tsurutani, J.; Seto, T.; Satouchi, M.; Tada, H.; Hirashima, T.; et al. Gefitinib versus cisplatin plus docetaxel in patients with non-small-cell lung cancer harbouring mutations of the epidermal growth factor receptor (WJTOG3405): An open label, randomised phase 3 trial. Lancet Oncol. 2010, 11, 121-128. [CrossRef]

7. Rosell, R.; Carcereny, E.; Gervais, R.; Vergnenegre, A.; Massuti, B.; Felip, E.; Palmero, R.; Garcia-Gomez, R.; Pallares, C.; Sanchez, J.M.; et al. Erlotinib versus standard chemotherapy as first-line treatment for European patients with advanced EGFR mutationpositive non-small-cell lung cancer (EURTAC): A multicentre, open-label, randomised phase 3 trial. Lancet Oncol. 2012, 13, 239-246. [CrossRef]

8. Wu, Y.L.; Zhou, C.; Hu, C.P.; Feng, J.; Lu, S.; Huang, Y.; Li, W.; Hou, M.; Shi, J.H.; Lee, K.Y.; et al. Afatinib versus cisplatin plus gemcitabine for first-line treatment of Asian patients with advanced non-small-cell lung cancer harbouring EGFR mutations (LUX-Lung 6): An open-label, randomised phase 3 trial. Lancet Oncol. 2014, 15, 213-222. [CrossRef]

9. Soria, J.C.; Ohe, Y.; Vansteenkiste, J.; Reungwetwattana, T.; Chewaskulyong, B.; Lee, K.H.; Dechaphunkul, A.; Imamura, F.; Nogami, N.; Kurata, T.; et al. Osimertinib in Untreated EGFR-Mutated Advanced Non-Small-Cell Lung Cancer. N. Engl. J. Med. 2018, 378, 113-125. [CrossRef] [PubMed]

10. Park, K.; Tan, E.H.; O’Byrne, K.; Zhang, L.; Boyer, M.; Mok, T.; Hirsh, V.; Yang, J.C.; Lee, K.H.; Lu, S.; et al. Afatinib versus gefitinib as first-line treatment of patients with EGFR mutation-positive non-small-cell lung cancer (LUX-Lung 7): A phase 2B, open-label, randomised controlled trial. Lancet Oncol. 2016, 17, 577-589. [CrossRef]

11. Paz-Ares, L.; Tan, E.H.; O’Byrne, K.; Zhang, L.; Hirsh, V.; Boyer, M.; Yang, J.C.; Mok, T.; Lee, K.H.; Lu, S.; et al. Afatinib versus gefitinib in patients with EGFR mutation-positive advanced non-small-cell lung cancer: Overall survival data from the phase IIb LUX-Lung 7 trial. Ann. Oncol. 2017, 28, 270-277. [CrossRef] [PubMed]

12. Mok, T.S.; Cheng, Y.; Zhou, X.; Lee, K.H.; Nakagawa, K.; Niho, S.; Lee, M.; Linke, R.; Rosell, R.; Corral, J.; et al. Improvement in Overall Survival in a Randomized Study That Compared Dacomitinib with Gefitinib in Patients with Advanced Non-Small-Cell Lung Cancer and EGFR-Activating Mutations. J. Clin. Oncol. 2018, 36, 2244-2250. [CrossRef] [PubMed] 
13. Wu, Y.L.; Cheng, Y.; Zhou, X.; Lee, K.H.; Nakagawa, K.; Niho, S.; Tsuji, F.; Linke, R.; Rosell, R.; Corral, J.; et al. Dacomitinib versus gefitinib as first-line treatment for patients with EGFR-mutation-positive non-small-cell lung cancer (ARCHER 1050): A randomised, open-label, phase 3 trial. Lancet Oncol. 2017, 18, 1454-1466. [CrossRef]

14. Gainor, J.F.; Shaw, A.T. Emerging paradigms in the development of resistance to tyrosine kinase inhibitors in lung cancer. J. Clin. Oncol. 2013, 31, 3987-3996. [CrossRef]

15. Kim, H.R.; Cho, B.C.; Shim, H.S.; Lim, S.M.; Kim, S.K.; Chang, J.; Kim, D.J.; Kim, J.H. Prediction for response duration to epidermal growth factor receptor-tyrosine kinase inhibitors in EGFR mutated never smoker lung adenocarcinoma. Lung Cancer 2014, 83, 374-382. [CrossRef] [PubMed]

16. Levy, B.P.; Rao, P.; Becker, D.J.; Becker, K. Attacking a Moving Target: Understanding Resistance and Managing Progression in EGFR-Positive Lung Cancer Patients Treated with Tyrosine Kinase Inhibitors. Oncology 2016, 30, 601-612.

17. Wang, J.; Wang, B.; Chu, H.; Yao, Y. Intrinsic resistance to EGFR tyrosine kinase inhibitors in advanced non-small-cell lung cancer with activating EGFR mutations. Onco Targets Ther. 2016, 9, 3711-3726. [CrossRef] [PubMed]

18. Blakely, C.M.; Bivona, T.G. Resiliency of lung cancers to EGFR inhibitor treatment unveiled, offering opportunities to divide and conquer EGFR inhibitor resistance. Cancer Discov. 2012, 2, 872-875. [CrossRef] [PubMed]

19. Cortot, A.B.; Janne, P.A. Molecular mechanisms of resistance in epidermal growth factor receptor-mutant lung adenocarcinomas. Eur. Respir. Rev. 2014, 23, 356-366. [CrossRef]

20. Yu, H.A.; Arcila, M.E.; Rekhtman, N.; Sima, C.S.; Zakowski, M.F.; Pao, W.; Kris, M.G.; Miller, V.A.; Ladanyi, M.; Riely, G.J. Analysis of tumor specimens at the time of acquired resistance to EGFR-TKI therapy in 155 patients with EGFR-mutant lung cancers. Clin. Cancer Res. 2013, 19, 2240-2247. [CrossRef]

21. Oxnard, G.R.; Arcila, M.E.; Sima, C.S.; Riely, G.J.; Chmielecki, J.; Kris, M.G.; Pao, W.; Ladanyi, M.; Miller, V.A. Acquired resistance to EGFR tyrosine kinase inhibitors in EGFR-mutant lung cancer: Distinct natural history of patients with tumors harboring the T790M mutation. Clin. Cancer Res. 2011, 17, 1616-1622. [CrossRef]

22. Sequist, L.V.; Waltman, B.A.; Dias-Santagata, D.; Digumarthy, S.; Turke, A.B.; Fidias, P.; Bergethon, K.; Shaw, A.T.; Gettinger, S.; Cosper, A.K.; et al. Genotypic and histological evolution of lung cancers acquiring resistance to EGFR inhibitors. Sci. Transl. Med. 2011, 3, 75ra26. [CrossRef] [PubMed]

23. Takeda, M.; Nakagawa, K. First- and Second-Generation EGFR-TKIs Are All Replaced to Osimertinib in Chemo-Naive EGFR Mutation-Positive Non-Small Cell Lung Cancer? Int. J. Mol. Sci. 2019, 20, 146. [CrossRef]

24. Wu, S.G.; Liu, Y.N.; Tsai, M.F.; Chang, Y.L.; Yu, C.J.; Yang, P.C.; Yang, J.C.; Wen, Y.F.; Shih, J.Y. The mechanism of acquired resistance to irreversible EGFR tyrosine kinase inhibitor-afatinib in lung adenocarcinoma patients. Oncotarget 2016, 7, 12404-12413. [CrossRef]

25. Goss, G.; Tsai, C.M.; Shepherd, F.A.; Bazhenova, L.; Lee, J.S.; Chang, G.C.; Crino, L.; Satouchi, M.; Chu, Q.; Hida, T.; et al. Osimertinib for pretreated EGFR Thr790Met-positive advanced non-small-cell lung cancer (AURA2): A multicentre, open-label, single-arm, phase 2 study. Lancet Oncol. 2016, 17, 1643-1652. [CrossRef]

26. Janne, P.A.; Yang, J.C.; Kim, D.W.; Planchard, D.; Ohe, Y.; Ramalingam, S.S.; Ahn, M.J.; Kim, S.W.; Su, W.C.; Horn, L.; et al. AZD9291 in EGFR inhibitor-resistant non-small-cell lung cancer. N. Engl. J. Med. 2015, 372, 1689-1699. [CrossRef]

27. Diaz, L.A., Jr.; Bardelli, A. Liquid biopsies: Genotyping circulating tumor DNA. J. Clin. Oncol. 2014, 32, 579-586. [CrossRef]

28. Kwapisz, D. The first liquid biopsy test approved. Is it a new era of mutation testing for non-small cell lung cancer? Ann. Transl. Med. 2017, 5, 46. [CrossRef]

29. Piotrowska, Z.; Niederst, M.J.; Karlovich, C.A.; Wakelee, H.A.; Neal, J.W.; Mino-Kenudson, M.; Fulton, L.; Hata, A.N.; Lockerman, E.L.; Kalsy, A.; et al. Heterogeneity Underlies the Emergence of EGFRT790 Wild-Type Clones Following Treatment of T790MPositive Cancers with a Third-Generation EGFR Inhibitor. Cancer Discov. 2015, 5, 713-722. [CrossRef] [PubMed]

30. Medina Diaz, I.; Nocon, A.; Mehnert, D.H.; Fredebohm, J.; Diehl, F.; Holtrup, F. Performance of Streck cfDNA Blood Collection Tubes for Liquid Biopsy Testing. PLoS ONE 2016, 11, e0166354. [CrossRef] [PubMed]

31. Diagnostics, R. Cobas Mutation Test v2. Available online: https://diagnostics.roche.com/global/en/products/params/cobasegfr-mutation-test-v2.html (accessed on 8 June 2021).

32. FDA. Cobas ${ }^{\circledR}$ EGFR Mutation Test v2 Indication. Available online: https://www.fda.gov/drugs/resources-informationapproved-drugs / cobas-egfr-mutation-test-v2 (accessed on 23 June 2021).

33. FDA. SUMMARY OF SAFETY AND EFFECTIVENESS DATA (SSED) cobas®EGFR Mutation Test v2. Available online: https: / / www.accessdata.fda.gov/cdrh_docs/pdf15/p150044b.pdf (accessed on 23 June 2021).

34. Gandara, D.R.; Li, T.; Lara, P.N.; Kelly, K.; Riess, J.W.; Redman, M.W.; Mack, P.C. Acquired resistance to targeted therapies against oncogene-driven non-small-cell lung cancer: Approach to subtyping progressive disease and clinical implications. Clin. Lung Cancer 2014, 15, 1-6. [CrossRef] [PubMed]

35. Gao, X.; Zhao, Y.; Bao, Y.; Yin, W.; Liu, L.; Liu, R.; Yu, Z.; Zhou, X.; Shuai, J. Poor Prognosis with Coexistence of EGFR T790M Mutation and Common EGFR-Activating Mutation in Non- Small Cell Lung Cancer. Cancer Manag. Res. 2019, 11, 9621-9630. [CrossRef]

36. Oxnard, G.R.; Miller, V.A.; Robson, M.E.; Azzoli, C.G.; Pao, W.; Ladanyi, M.; Arcila, M.E. Screening for germline EGFR T790M mutations through lung cancer genotyping. J. Thorac. Oncol. 2012, 7, 1049-1052. [CrossRef] 
37. Wu, J.Y.; Yu, C.J.; Chang, Y.C.; Yang, C.H.; Shih, J.Y.; Yang, P.C. Effectiveness of tyrosine kinase inhibitors on "uncommon" epidermal growth factor receptor mutations of unknown clinical significance in non-small cell lung cancer. Clin. Cancer Res. 2011, 17, 3812-3821. [CrossRef] [PubMed]

38. Linardou, H.; Kotoula, V.; Kouvatseas, G.; Mountzios, G.; Karavasilis, V.; Samantas, E.; Kalogera-Fountzila, A.; Televantou, D.; Papadopoulou, K.; Mavropoulou, X.; et al. Genotyping KRAS and EGFR Mutations in Greek Patients with Non-small-cell Lung Cancer: Incidence, Significance and Implications for Treatment. Cancer Genom. Proteom. 2019, 16, 531-541. [CrossRef] [PubMed]

39. Hochmair, M.J.; Buder, A.; Schwab, S.; Burghuber, O.C.; Prosch, H.; Hilbe, W.; Cseh, A.; Fritz, R.; Filipits, M. Liquid-BiopsyBased Identification of EGFR T790M Mutation-Mediated Resistance to Afatinib Treatment in Patients with Advanced EGFR Mutation-Positive NSCLC, and Subsequent Response to Osimertinib. Target. Oncol. 2019, 14, 75-83. [CrossRef] [PubMed]

40. Lau, S.C.; Chooback, N.; Ho, C.; Melosky, B. Outcome Differences between First- and Second-generation EGFR Inhibitors in Advanced EGFR Mutated NSCLC in a Large Population-based Cohort. Clin. Lung Cancer 2019, 20, e576-e583. [CrossRef]

41. Li, H.; Wang, J.; Zhang, G.; Li, Y.; Lin, L.; Yang, H.; Zhou, J.; Zhang, L.; Lv, D. Detection of plasma T790M mutation after the first generation EGFR-TKI resistance of non-small cell lung cancer in the real world. J. Thorac. Dis. 2020, 12, 550-557. [CrossRef]

42. Nosaki, K.; Satouchi, M.; Kurata, T.; Yoshida, T.; Okamoto, I.; Katakami, N.; Imamura, F.; Tanaka, K.; Yamane, Y.; Yamamoto, N.; et al. Re-biopsy status among non-small cell lung cancer patients in Japan: A retrospective study. Lung Cancer 2016, 101, 1-8. [CrossRef]

43. Papadopoulou, E.; Tsoulos, N.; Tsantikidi, K.; Metaxa-Mariatou, V.; Stamou, P.E.; Kladi-Skandali, A.; Kapeni, E.; Tsaousis, G.; Pentheroudakis, G.; Petrakis, D.; et al. Clinical feasibility of NGS liquid biopsy analysis in NSCLC patients. PLoS ONE 2019, 14, e0226853. [CrossRef]

44. Kim, H.; Jung, H.A.; Lee, S.H.; Ahn, J.S.; Ahn, M.J.; Park, K.; Sun, J.M. Comprehensive evaluation of the clinical utility of plasma EGFR test in non-small cell lung cancer patients with acquired resistance to first-line EGFR inhibitors. Transl. Lung Cancer Res. 2021, 10, 878-888. [CrossRef]

45. Li, X.; Zhou, C. Comparison of cross-platform technologies for EGFR T790M testing in patients with non-small cell lung cancer. Oncotarget 2017, 8, 100801-100818. [CrossRef]

46. Jenkins, S.; Yang, J.C.; Janne, P.A.; Thress, K.S.; Yu, K.; Hodge, R.; Weston, S.; Dearden, S.; Patel, S.; Cantarini, M.; et al. EGFR Mutation Analysis for Prospective Patient Selection in Two Phase II Registration Studies of Osimertinib. J. Thorac. Oncol. 2017, 12, 1247-1256. [CrossRef]

47. Cho, M.S.; Park, C.H.; Lee, S.; Park, H.S. Clinicopathological parameters for circulating tumor DNA shedding in surgically resected non-small cell lung cancer with EGFR or KRAS mutation. PLoS ONE 2020, 15, e0230622. [CrossRef]

48. Kim, T.O.; Oh, I.J.; Kho, B.G.; Park, H.Y.; Chang, J.S.; Park, C.K.; Shin, H.J.; Lim, J.H.; Kwon, Y.S.; Kim, Y.I.; et al. Feasibility of re-biopsy and EGFR mutation analysis in patients with non-small cell lung cancer. Thorac. Cancer 2018, 9, 856-864. [CrossRef]

49. Karlovich, C.; Goldman, J.W.; Sun, J.M.; Mann, E.; Sequist, L.V.; Konopa, K.; Wen, W.; Angenendt, P.; Horn, L.; Spigel, D.; et al. Assessment of EGFR Mutation Status in Matched Plasma and Tumor Tissue of NSCLC Patients from a Phase I Study of Rociletinib (CO-1686). Clin. Cancer Res. 2016, 22, 2386-2395. [CrossRef] [PubMed]

50. Thress, K.S.; Brant, R.; Carr, T.H.; Dearden, S.; Jenkins, S.; Brown, H.; Hammett, T.; Cantarini, M.; Barrett, J.C. EGFR mutation detection in ctDNA from NSCLC patient plasma: A cross-platform comparison of leading technologies to support the clinical development of AZD9291. Lung Cancer 2015, 90, 509-515. [CrossRef]

51. Papadimitrakopoulou, V.A.; Han, J.Y.; Ahn, M.J.; Ramalingam, S.S.; Delmonte, A.; Hsia, T.C.; Laskin, J.; Kim, S.W.; He, Y.; Tsai, C.M.; et al. Epidermal growth factor receptor mutation analysis in tissue and plasma from the AURA3 trial: Osimertinib versus platinum-pemetrexed for T790M mutation-positive advanced non-small cell lung cancer. Cancer 2020, 126, 373-380. [CrossRef]

52. Ntzifa, A.; Kroupis, C.; Haliassos, A.; Lianidou, E. A pilot plasma-ctDNA ring trial for the Cobas(R) EGFR Mutation Test in clinical diagnostic laboratories. Clin. Chem. Lab. Med. 2019, 57, e97-e101. [CrossRef] [PubMed]

53. Wang, H.; Zhang, L.; Si, X.; Zhang, X.; Wang, M. Re-biopsy status among Chinese non-small-cell lung cancer patients who progressed after icotinib therapy. Onco Targets Ther. 2018, 11, 7513-7519. [CrossRef] [PubMed]

54. Tan, D.S.; Yom, S.S.; Tsao, M.S.; Pass, H.I.; Kelly, K.; Peled, N.; Yung, R.C.; Wistuba, I.I.; Yatabe, Y.; Unger, M.; et al. The International Association for the Study of Lung Cancer Consensus Statement on Optimizing Management of EGFR MutationPositive Non-Small Cell Lung Cancer: Status in 2016. J. Thorac. Oncol. 2016, 11, 946-963. [CrossRef] [PubMed]

55. Jenkins, S.; Yang, J.C.; Ramalingam, S.S.; Yu, K.; Patel, S.; Weston, S.; Hodge, R.; Cantarini, M.; Janne, P.A.; Mitsudomi, T.; et al. Plasma ctDNA Analysis for Detection of the EGFR T790M Mutation in Patients with Advanced Non-Small Cell Lung Cancer. J. Thorac. Oncol. 2017, 12, 1061-1070. [CrossRef]

56. Matsuo, N.; Azuma, K.; Sakai, K.; Hattori, S.; Kawahara, A.; Ishii, H.; Tokito, T.; Kinoshita, T.; Yamada, K.; Nishio, K.; et al. Association of EGFR Exon 19 Deletion and EGFR-TKI Treatment Duration with Frequency of T790M Mutation in EGFR-Mutant Lung Cancer Patients. Sci. Rep. 2016, 6, 36458. [CrossRef] [PubMed]

57. Ko, R.; Kenmotsu, H.; Serizawa, M.; Koh, Y.; Wakuda, K.; Ono, A.; Taira, T.; Naito, T.; Murakami, H.; Isaka, M.; et al. Frequency of EGFR T790M mutation and multimutational profiles of rebiopsy samples from non-small cell lung cancer developing acquired resistance to EGFR tyrosine kinase inhibitors in Japanese patients. BMC Cancer 2016, 16, 864. [CrossRef]

58. Tseng, J.S.; Su, K.Y.; Yang, T.Y.; Chen, K.C.; Hsu, K.H.; Chen, H.Y.; Tsai, C.R.; Yu, S.L.; Chang, G.C. The emergence of T790M mutation in EGFR-mutant lung adenocarcinoma patients having a history of acquired resistance to EGFR-TKI: Focus on rebiopsy timing and long-term existence of T790M. Oncotarget 2016, 7, 48059-48069. [CrossRef] 